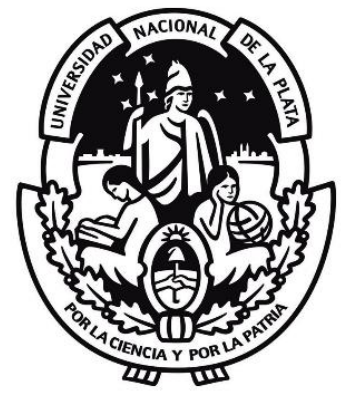

UNIVERSIDAD NACIONAL DE LA PLATA FACULTAD DE BELLAS ARTES

MAESTRÍA EN PSICOLOGÍA DE LA MÚSICA

\title{
LA MEMORIZACIÓN DE MÚSICA CONTRAPUNTÍSTICA
}

Un estudio de caso de las estrategias empleadas por

una pianista profesional

TESIS DE MAESTRÍA

MAXIMILIANO ANDRÉS BERTEA

\section{DIRECCIÓN}

DRA. SILVIA RAQUEL MALBRÁN

DRA. MARÍA DEL CARMEN MALBRÁN

La Plata, noviembre 2017 
A Silvia 


\section{ÍNDICE}

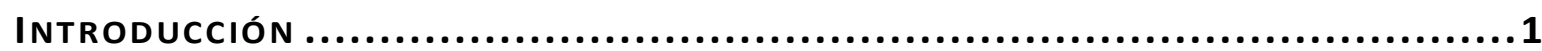

\section{PARTE I}

\section{FUNDAMENTOS TEÓRICOS}

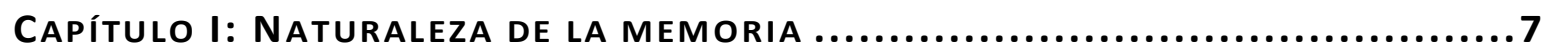

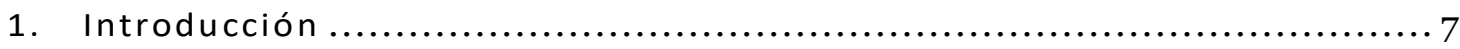

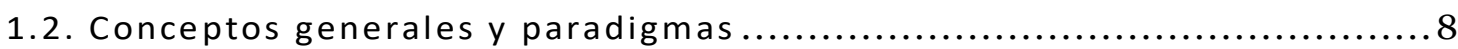

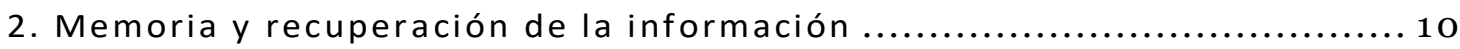

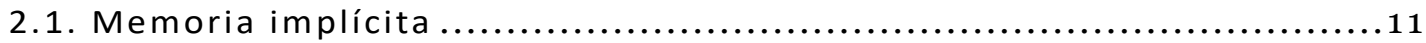

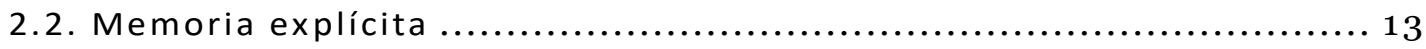

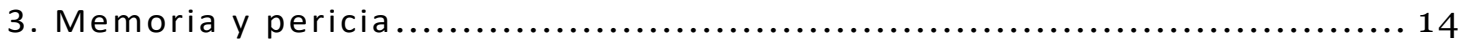

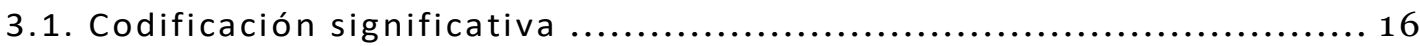

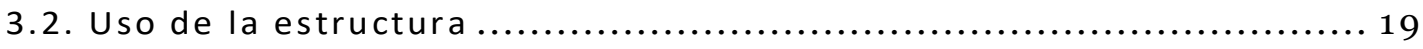

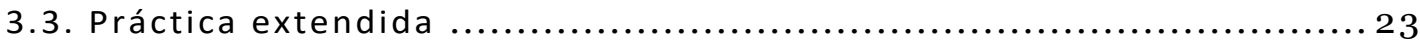

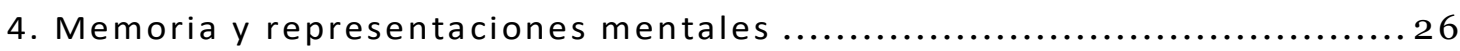

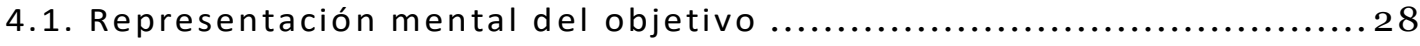

4.2. Representación mental de la ejecución en tiempo real ...............29

4.3. Representación mental de los aspectos de producción.................31

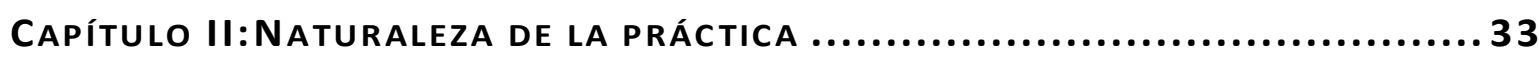

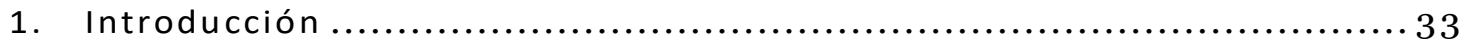

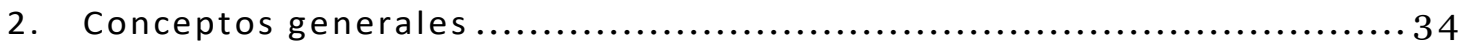

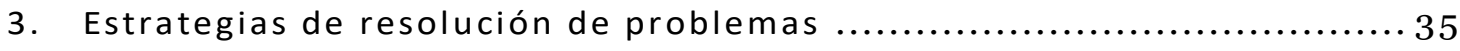

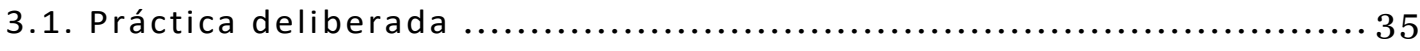

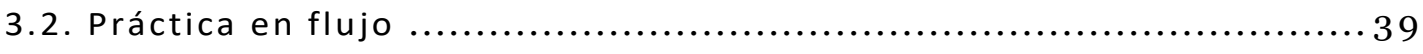

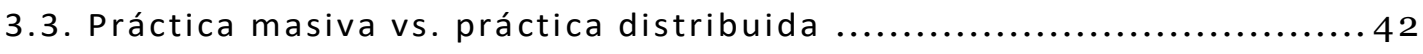




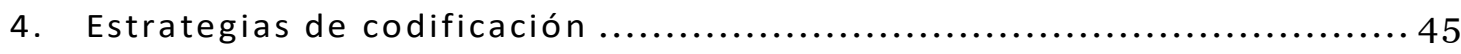

4.1. Práctica mental................................................. 45

4.2. Procesamiento de la información .................................... 50

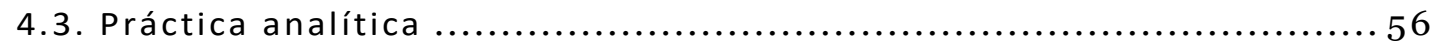

4. Estrategias de recuperación ............................................ 57

5.1. Enculturación y experiencia............................................ 58

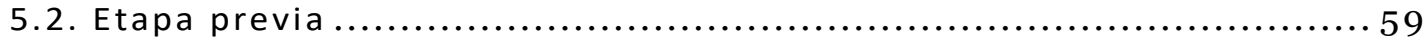

5.3. Etapa de la práctica .................................................. 61

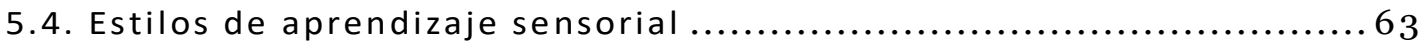

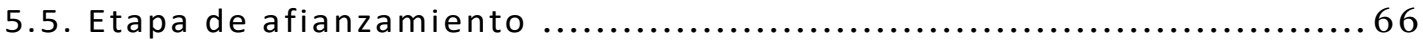

\section{PARTE II}

\section{EVIDENCIA EMPÍRICA}

Capítulo ill: Objetivos y Metodología.................................... 70

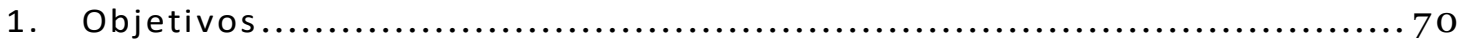

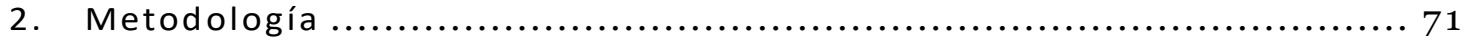

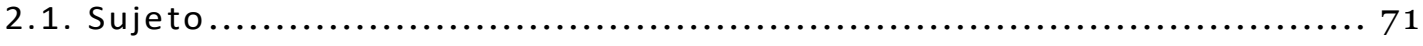

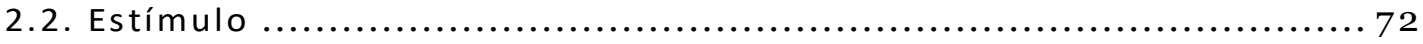

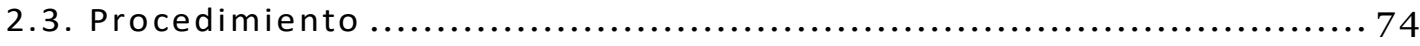

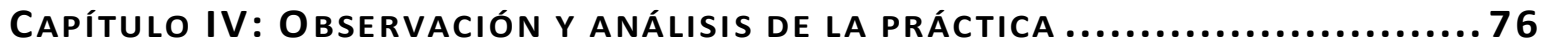

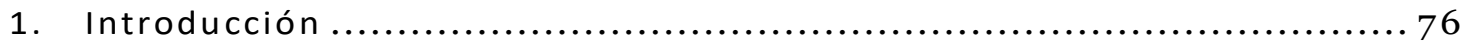

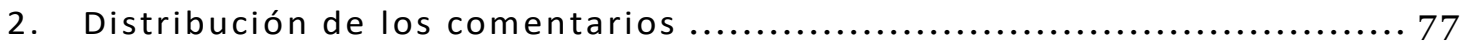

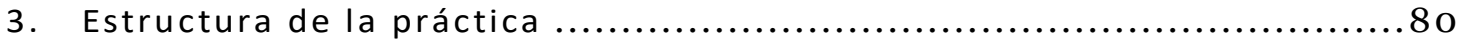

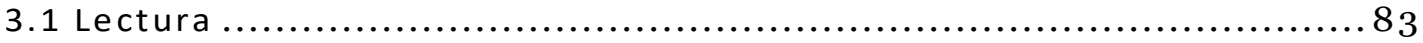

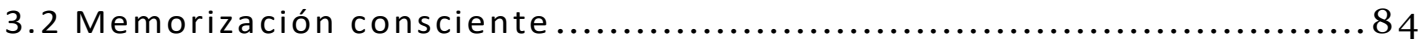

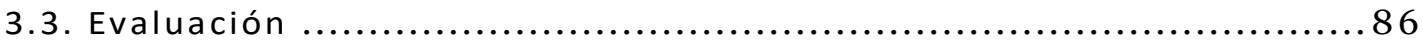


4. Componentes de la práctica ............................................... 88

4.1. Identificación de patrones y uso de la estructura .......................88

4.2. Reconocimiento y corrección de errores ..............................90

4.3. Procesamiento de la información .................................... 94

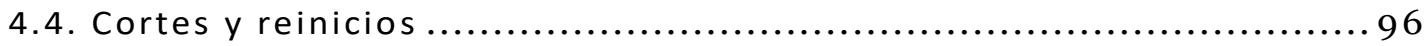

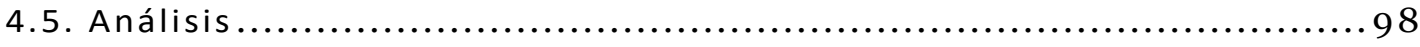

4.6. Práctica mental...................................................... 99

4.7. Estilos sensoriales ................................................. 100

Capítulo V: Conclusiones .............................................. 103

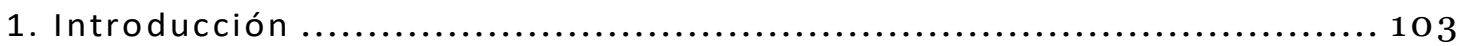

2. Síntesis y discusión de la evidencia empírica .......................... 104

2.1. La relación estructura - textura .................................... 106

2.2. Lo explícito y lo implícito en la práctica instrumental ................109

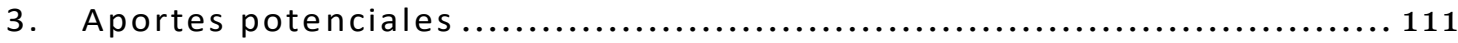

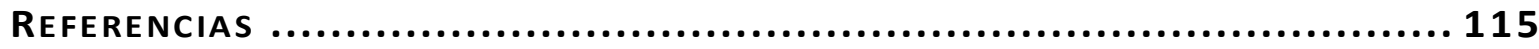




\section{INTRODUCCIÓN}

Esta tesis presenta un estudio de caso basado en la observación de las estrategias empleadas por una pianista experta durante la memorización de una obra contrapuntística imitativa.

Tocar de memoria es una práctica generalizada en muchos géneros musicales y diferentes pedagogos han coincidido en que el acto mismo de memorizar puede garantizar un conocimiento más profundo y una conexión íntima con la música (Matthay, 1926). La ejecución sin partitura facilita el contacto visual con el público y los músicos que lo hacen encuentran probablemente una respuesta más sensible del público (Davidson, 1993, 1994; Williamon, 1999).

Los primeros aportes en relación a la memoria musical en la ejecución datan de comienzos del siglo XX. Se trata, en la mayoría de los casos, de textos pedagógicos o de estudios esporádicos y no sistemáticos, de corte más descriptivo que experimental. Sin embargo, estas contribuciones merecen ser reconocidas, como ya lo han señalado algunos autores (Gellrich, 1987).

La memorización suele ser una tarea ardua, tanto para expertos como para principiantes alcanzando el mayor grado de complejidad en la música contrapuntística (Tureck, 1960) Las obras construidas sobre la base del contrapunto imitativo (siendo quizá la fuga el 


\section{Introducción}

ejemplo por excelencia) han representado un escollo aún en intérpretes experimentados que no encuentran problemas en la memorización de otro tipo de discursos. En el caso de las fugas u otras texturas construidas sobre la base de la imitación, el ejecutante debe poner en juego particulares estrategias para la codificación de la obra, con miras a su recuperación durante la ejecución sin partitura.

Investigaciones preliminares (Chaffin \& Imreh, 1997) han explorado el rol que juega la estructura jerárquica de la música en los procesos de codificación y recuperación del material alojado en la memoria a largo plazo. No obstante, los estudios vinculados a la ejecución musical no se han ocupado suficientemente de la memorización de discursos contrapuntísticos por parte de instrumentistas expertos. Es por ello que esta investigación se propone explorar y describir las estrategias de práctica empleadas por un profesional durante el proceso de memorización de una obra contrapuntística.

La elección del tema surge de mi experiencia como pianista y docente de instrumento en diferentes niveles e instituciones. Uno de los desafíos centrales de la discusión actual es observar la práctica instrumental en tanto objeto real construido en un interjuego continuo entre lo teórico y lo empírico. Es necesario señalar que el contexto en que tienen lugar estas discusiones es siempre complejo, dado que los múltiples escenarios en que transcurre la práctica instrumental (la clase de instrumento, la práctica personal) son más 


\section{Introducción}

bien herméticos y están fuertemente atravesados por la tradición decimonónica. Ello conlleva un fuerte rechazo - a veces taxativo- a la mirada del investigador y a la cientificidad de algunos enfoques (Gellrich, 1987; Mahlert, 2006).

El texto se organiza en dos partes: la primera, en dos capítulos, está dedicada a delinear los fundamentos teóricos que sirven de marco conceptual al tema sobre la base de dos temáticas centrales para los estudios sobre ejecución musical: la memoria y la práctica. Se propone no solo una lectura y descripción del tema, sino un análisis crítico de la bibliografía y un relevo de la investigación de data más reciente, así como también de los textos pedagógicos especializados en la enseñanza y la práctica instrumental.

La segunda parte reúne, en dos capítulos, la evidencia empírica recogida en el estudio de caso en cuestión. El capítulo 3 describe la metodología empleada, la cual responde a diseños adoptados ya por la investigación especializada en los estudios sobre práctica y memoria (Hallam, 1995; Chaffin \& Imreh, 1997) y los objetivos del trabajo. El capítulo 4 presenta el relevamiento y análisis de la información obtenida, a la luz del marco teórico expuesto en la primera parte de la tesis.

Por último, el capítulo 5 está destinado a las conclusiones: se presenta en él una síntesis y discusión de la evidencia empírica recogida en el estudio de caso llevado a cabo y señala posibles 
aportes de la tesis en relación a la práctica instrumental y a futuras investigaciones.

Quisiera expresar mi profunda gratitud a quienes de diferente manera colaboraron en la concreción de este trabajo: a la pianista Melina Marcos, por su predisposición incondicional y desinteresada, a mis colegas y alumnos de las instituciones en las que he trabajado durante los años en que esta investigación tuvo lugar. Estas páginas son también el resultado de los aportes que ellos han hecho: al Instituto de Formación Docente Continua de Villa Mercedes (San Luis), a la Facultad de Artes de la Universidad Nacional de Córdoba, al Conservatorio Superior de Música "Astor Piazzolla" y a la ESEAM "Juan Pedro Esnaola" de la Ciudad Autónoma de Buenos Aires.

A Esteban, por el álgebra platense. A Cecilia Zárate, Daniel Callejas y Cecilia Garay por los aportes que hicieron en la lectura del escrito. A Marisol Iturralde y a Gisela Bertea, por los aportes en la elaboración del anteproyecto.

No puedo dejar de señalar que inicialmente la dirección de esta tesis y la corrección de los primeros borradores estuvieron a cargo de la Dra. Silvia Raquel Malbrán, quien incluso en las situaciones más difíciles de salud que precedieron a su muerte, fue un sostén y estímulo permanente. La finalización no hubiera sido posible sin la generosidad de la Dra. María del Carmen Malbrán, quien no solo 


\section{Introducción}

aceptó continuar la dirección de un trabajo en cuyas disposiciones iniciales no había intervenido, sino que realizó contribuciones de inestimable valor para el análisis de la evidencia empírica, las conclusiones y la organización final de este escrito. 


\section{PARTE I}

FUNDAMENTOS TEÓRICOS 


\section{CAPÍtulo I}

\section{NATURALEZA DE LA MEMORIA}

\section{$1.1 \quad$ Introducción}

En este capítulo se presentan y describen conceptos generales y paradigmas de la Psicología de la Memoria y su impacto en los estudios vinculados a la ejecución musical. Los aportes de la investigación en las últimas décadas han permitido un conocimiento más cabal sobre la estructura y el funcionamiento de la memoria humana, ampliando el horizonte de estas búsquedas al terreno de la interpretación musical con un nuevo desafío: explicar la coexistencia de lo automatizado y lo conceptual de la ejecución sin partitura en tiempo real. Se analizan a continuación los principios de memoria experta así como también los procesos que permiten la codificación y recuperación de la información. Por último se describe el rol de las representaciones mentales en la memorización e interpretación musicales. 


\subsection{Conceptos generales y paradigmas}

La Psicología se ha ocupado del estudio de la memoria. Atkinson \& Shiffrin, (1968) postularon un modelo teórico que sentó las bases para explicar su funcionamiento y los procesos que involucra. Este modelo, conocido como modelo modal o multi-almacén, adopta un enfoque estructuralista según el cual es posible diferenciar tres tipos de memoria: (i) sensorial, (ii) a corto plazo (MCP) y (iii) a largo plazo (MLP).

La memoria sensorial (i) involucra procesos básicos del sistema cognitivo en la recepción de estímulos ambientales que tienen una permanencia muy breve.

La memoria a corto plazo (ii) es un almacenamiento de capacidad limitada que juega sin embargo un papel crucial en nuestra vida diaria. Una de las funciones centrales es la de mantener la información necesaria para poder realizar una tarea presente (e.g. seguir una conversación). En la ejecución musical es parte sustancial de actividades tales como la lectura a primera vista y la improvisación (Thompson, 2004). Muchas de las patologías que asociamos a la pérdida de memoria y a la dificultad de procesamiento de información en adultos mayores tienen que ver con un deterioro de este tipo de almacenamiento.

La capacidad de la MCP es pequeña y está limitada a un número de 5 (+/ 2) ítems o bits de información que se conoce como el número mágico de Miller (Miller, 1956). Otra característica de este tipo de memoria es el 


\section{Capítulo I- Naturaleza de la memoria}

olvido que tiene lugar en el momento inmediato posterior a la presentación del estímulo. A medida que el número 7 comienza a ser sobrepasado la entrada de nuevos datos va amenazando la estabilidad de la información anterior.

Atendiendo a la ocurrencia temporal de los estímulos y al orden que éstos tienen en la cadena, se ha observado que los primeros y últimos ítems son recordados mejor que los intermedios. Se conoce como efecto de primacía al que designa la prevalencia de los primeros ítems de la cadena y efecto de recencia a la preeminencia de los últimos de la cadena (Snyder, 2000). La curva del recuerdo podría graficarse entonces como una $U$ disimétrica ${ }^{1}$ cuyos extremos (los efectos que hemos mencionado) no se ubican en el mismo nivel. En el caso de un recuerdo inmediato el efecto de recencia es mayor mientras que en el recuerdo diferido el efecto de primacía es mayor (Rossi, 2005). En cuanto al comportamiento neuronal la MCP no produce cambios permanentes en las conexiones neuronales como ocurre con la memoria a largo plazo (Squire \& Kandel, 1999 en Snyder, 2000).

La memoria a largo plazo (iii) -a diferencia de la MCP- tiene una capacidad ilimitada de almacenamiento que se mantiene disponible por tiempo indefinido. Dicha capacidad puede ser aprendida y desarrollada a

\footnotetext{
1 Entendiendo por disimetría una falla dentro de algo simétrico antes que una ausencia total de simetría.
} 
lo largo de todo el ciclo vital y contiene los conocimientos y creencias que el ser humano ha adquirido en el curso de su existencia. El almacenamiento es definitivo y el olvido está vinculado con las dificultades e interferencias que surgen en la recuperación de la información (Rossi, 2005). La información alojada en la MLP permanece normalmente inactiva o latente, y sólo son recuperados fragmentos de información cuando algún tipo de demanda lo requiere (de Vega, 1990).

\section{Memoria y recuperación de la información}

La información alojada en la MLP no siempre es accesible a la conciencia: mientras que parte de la información se encuentra en el foco del conocimiento consciente, otras necesitan ser recuperadas del inconsciente. En las situaciones de olvido que todos experimentamos a diario, lo que se olvida no es la información almacenada sino las conexiones que permiten el acceso a ella (Rossi, 2005; Fuster 1995 en Snyder, 2000). Cuando una información es recuperada el contexto de recuperación se enriquece con el auxilio de nuevas pistas y conexiones. Por ello el desafío central de la MLP es conservar la asociación entre una pista y la información específica y evitar que otras pistas produzcan algún tipo de interferencia (Snyder, 2000). En síntesis: el almacenamiento en la MLP es definitivo, pero la activación de la información puede sufrir dificultades. 


\section{Capítulo I- Naturaleza de la memoria}

Es necesario que parte de la información almacenada se mantenga inconsciente (fuera del campo de la conciencia en un nivel más profundo), para dejar lugar al presente consciente en el que la información se encuentra en el mayor grado de activación. Para explicar esta dicotomía los psicólogos han distinguido dos tipos de memoria: implícita y explícita.

\subsection{Memoria implícita}

Gran parte de los contenidos almacenados en la memoria no son verbalizables ni accesibles a la conciencia en forma directa. Algunos autores han sostenido que se trataría de un sistema anterior al desarrollo de formas más conscientes de memoria (Reber, 1989). Los grupos neuronales involucrados en el aprendizaje implícito no estarían aparentemente conectados con los que procesan la información lingüística.

Los contenidos de la memoria implícita son difíciles de examinar conscientemente. Algunas publicaciones recientes han recogido el testimonio de instrumentistas prominentes sobre temas tales como la práctica, la memorización, la adquisición y mantenimiento del repertorio y demás cuestiones referidas al oficio del intérprete (Chaffin et al., 2002; Wessel, 2012). Al ser consultados sobre la memorización, una de las expresiones recurrentes entre los entrevistados es que la memoria "simplemente ocurre". Es posible explicar esta afirmación en tanto algunas memorias se desarrollan como subproductos de la práctica 


\section{Capítulo I- Naturaleza de la memoria}

repetitiva y serían relativamente inflexibles. El viejo adagio que proclamaba la dificultad o imposibilidad de corregir el error encierra una gran dosis de verdad: corregir implica anexar y de ninguna manera reemplazar una información por otra (i.e. la digitación de un pasaje).

Las destrezas de tipo motor que se ponen en juego al tocar un instrumento remiten a este tipo de memoria cuya ubicación en el cerebro sería distinta a la de la memoria explícita. Si bien la información alojada es por un lado relativamente inflexible, por otro es rápida y automáticamente recuperable sin esfuerzo consciente (Snyder, 2000).

La interacción entre memoria explícita e implícita se ubica en el centro de las indagaciones sobre la memorización para la ejecución. La memoria implícita en la ejecución musical juega un rol indiscutible: el ensayo repetido persigue entre otros objetivos la automatización de los aspectos más esenciales de una ejecución. Se ponen en juego conocimientos y destrezas adquiridos en experiencias previas vinculadas a la sintaxis, la armonía y la forma pero también a patrones musculares referidos a destrezas motoras específicas de cada instrumento.

Esta incidencia de la experiencia previa en la recuperación sin esfuerzo consciente (fenómeno que se conoce con el nombre de Priming) permite que en la vida diaria reconozcamos objetos o personas y podamos nombrarlos. En el campo de la ejecución musical la lectura a primera vista y la improvisación son claros ejemplos de un reconocimiento no consciente que nos permite operar al instante. 


\subsection{Memoria explícita}

La memoria declarativa o explícita comprende diversas capacidades que nos permiten la codificación y recuperación consciente de la información. Puede ser expresada en palabras o imágenes. Endel Tulving (1972 y 1983 en Snyder, 2000) postuló una distinción entre memoria episódica y memoria semántica.

La memoria episódica comprende eventos o experiencias específicos en la vida de la persona, por lo cual se habla a veces de memoria autobiográfica. Este tipo de memoria sería altamente susceptible a la distorsión en tanto el acto de recordar se repita, ya que el recuerdo es un proceso dinámico en el que los detalles pueden verse alterados y modificados. Lo que conocemos como amnesia no es sino una pérdida de la memoria episódica.

La memoria semántica refiere a conceptos abstractos o categorías que a diferencia de la episódica no están organizados de manera temporal o espacial. Cuando hablamos de "saber algo" por oposición a "recordar", estamos refiriéndonos a este tipo de memoria (Snyder, 2000; Ginsborg, 2004). Existe una relación en cierto grado interdependiente entre estas memorias: las memorias episódicas no se construyen exclusivamente desde la experiencia sino recurriendo al menos en parte a la memoria semántica y viceversa (D'Andrade, 1995 en Snyder, 2000). La repetición 


\section{Capítulo I- Naturaleza de la memoria}

permite además la evocación automática de la memoria semántica que llega a ser entonces implícita.

Chaffin et al (2002) recogieron, categorizaron y compararon los comentarios de los pianistas más sobresalientes del último tiempo sobre el tema memoria. Si bien los testimonios fueron recogidos en diferentes momentos y formatos (y no "ad hoc" para el estudio), el análisis y categorización de los relatos revela puntos de coincidencia entre los entrevistados. Se observó un marcado consenso acerca del empleo de la memoria auditiva y motora, por oposición al uso de la memoria visual en el que se evidenciaron mayores diferencias. La memoria declarativa ${ }^{2}$ es mencionada escasamente por los pianistas entrevistados; quienes si bien mencionan conceptos tales como la estructura formal y el análisis armónico, no los vinculan directamente a la memorización y prefieren considerarlo algo fortuito que ocurre sin ningún esfuerzo consciente.

\section{Memoria y pericia}

El concepto de pericia comprende los diversos mecanismos que permiten alcanzar altos niveles de desempeño en una tarea determinada. Un

2 Los autores prefieren la denominación antigua "memoria conceptual" por considerarla más accesible al público lector menos familiarizado con la terminología específica. 


\section{Capítulo I- Naturaleza de la memoria}

experto es aquel que ha desarrollado destrezas y/o conocimientos en determinada área por medio de la práctica y la experiencia. Los casos en los que un sujeto logra un desempeño marcadamente excepcional (ya sea un deportista, compositor, científico, etc.) plantean controversias con quienes se resisten a abandonar la idea del talento (la sola posibilidad de cuestionar el concepto provocaría un cataclismo en cualquier institución de enseñanza musical). Los intentos por vincular el desempeño excepcional con una predisposición o talento naturales han fracasado en todos los casos (Ericsson \& Lehmann, 2011) aun cuando gocen de amplia aceptación en el imaginario popular. El rol de la práctica en la adquisición de destrezas es examinado en el segundo capítulo de este trabajo.

La capacidad de memorizar con una facilidad casi "sobrehumana" aparece como un indicador típico de pericia. La Psicología ha investigado la memoria experta en campos en los cuales la preminencia de la memoria declarativa es ostensible (e.g. jugadores de ajedrez o experimentos de memorización con cadenas de números). No puede concluirse sin embargo que las mismas consideraciones sean aplicables a la ejecución musical en la que la memoria implícita juega un papel central.

Las investigaciones llevadas a cabo por el psicólogo Roger Chaffin y la pianista Gabriela Imreh constituyen el primer antecedente del estudio de la memoria experta en la ejecución musical (Chaffin \& Imreh, 1997). Los autores se plantean dos interrogantes: en qué medida los marcos 
teóricos sobre memoria experta son aplicables a la ejecución musical y qué piensa la pianista mientras toca.

Gabriela Imreh grabó todas las sesiones de práctica del tercer movimiento (Presto) del Concierto Italiano de Johann Sebastian Bach, desde el primer encuentro con la partitura hasta la memorización. En las videograbaciones es posible escuchar los comentarios de la instrumentista con relación al aprendizaje de la obra.

La investigación ha postulado la existencia de tres principios para la memorización experta (Ericsson, 1985): (i) codificación significativa, (ii) uso de la estructura y (iii) práctica extendida. Si bien dichos principios describen campos en los que la memoria declarativa juega un rol central (a diferencia de la ejecución musical en la que la memoria implícita es crucial), la investigación de Chaffin y sus colegas demostró que la memoria declarativa es tan importante en pianistas profesionales como en expertos en otros campos.

\subsection{Codificación significativa}

El primer principio de memoria experta está referido al proceso de codificación por el cual la información entrante es procesada y transferida a la MLP. La codificación involucra un conjunto de operaciones mentales orientadas al almacenamiento de la información, 


\section{Capítulo I- Naturaleza de la memoria}

transformando los estímulos sensoriales en pautas de información que sean significativas y asimilables por la memoria (de Vega, 1990). Diversos estudios en otros dominios en los que la memoria se pone en juego han sido cruciales para describir la memorización experta. Los considerados pioneros en el campo fueron realizados con ajedrecistas (Chase \& Ericsson, 1982 y Chase \& Simon, 1973 en Chaffin \& Logan 2006), con órdenes de comida en restaurantes (Ericsson \& Oliver, 1989 en Chaffin \& Logan, 2006) y sujetos memorizando cadenas numéricas.

Chase y Ericsson (1981) realizaron un estudio en que pidieron a los sujetos que memorizaron una larga cadena de números dispuestos aleatoriamente y cuya extensión fue aumentando. La extensión que la mayoría de la gente puede recordar es de siete dígitos. Un sujeto, identificado con las iniciales SF ejercitó durante 200 horas y fue capaz de recordar hasta 80 números (un número nunca alcanzado por nadie). La fase de aprendizaje fue monitoreada por los autores que observaron que SF había codificado la información en grupos de cuatro dígitos como una duración (9438 se transformó en nueve minutos 43,8 segundos). La estrategia aplicada por SF tenía estrecha vinculación con sus conocimientos sobre competencias de atletismo: SF era un corredor semiprofesional que pudo vincular cada grupo de cuatro números con tiempos alcanzados por atletas en diferentes competencias. La cadena de 80 números se economizó entonces en 20 marcas de torneos de atletismo. 


\section{Capítulo I- Naturaleza de la memoria}

El sujeto SF es un experto en tanto es capaz de llevar a cabo una tarea en un grado significativamente mejor (debiendo establecerse cuál es el criterio) que el resto de la gente. Esta definición planteada por John Sloboda (1991) deja abierta la posibilidad de relativizar los alcances del concepto de pericia ya que no existe un límite inferior en la relación a la complejidad o especificidad de la tarea. Al analizar el caso de SF, Sloboda (1991) rescata la existencia de experiencias previas que le permitieron acrecentar su habilidad en la tarea de memorización.

El conocimiento que un experto tiene de su campo le permite codificar el material nuevo en términos de estructuras ya almacenadas en la memoria (Bousfield, 1953; Mandler \& Pearstone, 1966; Tulving 1962 en Chaffin et al. 2002). Un instrumentista se ha entrenado durante años en la práctica de escalas, arpegios, progresiones armónicas, etc., de suerte que la información entrante pueda ser codificada en estructuras más grandes en expertos que en novicios. Además los músicos más experimentados muestran ser capaces de tomar decisiones de manera repentina frente a situaciones complejas (Gober \& Simon, 1996b en Chaffin et al. 2002).

En el marco de los estudios cognitivos sobre la memoria, Brown \& Craik (2000) señalaron diversos factores que condicionan el éxito del proceso de codificación, los cuales son aplicables a la ejecución musical:

- Presencia de objetivos y metas claras: la reflexión sobre el propio pensamiento (metacognición) y la planificación son cruciales; no practicar jamás bajo el "principio de la esperanza" (Mantel, 2001). 


\section{Capítulo I- Naturaleza de la memoria}

- Tipo de práctica: el almacenamiento pasivo que supone la mera repetición (típica en novatos) por oposición a una práctica en la que se establecen relaciones significativas entre la información entrante y la ya existente.

- Distribución temporal: hay consenso entre los autores en que la práctica distribuida es preferible a la práctica masiva (Barry \& Hallam, 2002). La razón es que los intervalos de tiempo permitirían una reacomodación diferente a la primera presentación y por ende una codificación más elaborada y con mayores asociaciones (Mornell \& Wulf, 2008).

- Organización: referido al agrupamiento de los eventos en unidades significativas más grandes (e.g. una frase musical o motivo). Los expertos serían aquellos capaces de operar con estructuras más extensas y complejas (Chaffin et al. 2002)

\subsection{Uso de la estructura}

El empleo de una estructura de recuperación bien aprendida es fundamental para un uso experto de la memoria en cualquier campo. En el caso de la ejecución musical la estructura misma de la obra provee una organización jerárquica de la cual el intérprete se sirve (Chaffin \& Imreh, 1997; Snyder, 2000). La pianista de la investigación de Chaffin (1997) 


\section{Capítulo I- Naturaleza de la memoria}

estudió el Presto del Concierto Italiano de Bach y el objetivo fue integrar manos y cabeza. En otras palabras: la meta de la práctica fue lograr que la memoria explícita (considerablemente más lenta) coincidiera con la motora.

Es posible preguntarse sobre la importancia de la memoria explícita y argumentar prima facie que el solo uso de ella sería más económico a los fines de la ejecución musical. Sin embargo, en diversas situaciones el control consciente de la situación resulta imprescindible. Cuando un intérprete tiene un fallo de memoria, necesita valerse de su memoria explícita para recuperarse y seguir adelante. Existen además momentos puntuales en una obra en los que el cambio de una sola nota conduce a secciones distintas (e.g. las repeticiones de un estribillo en una forma rondó) y en estos casos el monitoreo del ejecutante es crucial.

Palmer (2006) señala que uno de los problemas que plantean los estudios de memoria para la ejecución es responder cuáles serían las características de la Música que se representan en la memoria. Atkinson \& Shiffrin (1968) señalan que la MLP es tan amplia que se vuelve imprescindible emplear una clave o pista que permita la recuperación.

El concepto clave acuñado por Chaffin (2002) es el de pistas performativas (PP) y refiere a aquellas características que captan la atención del músico durante la ejecución. En el transcurso de la práctica el intérprete toma numerosas decisiones sobre distintos aspectos (e.g. 


\section{Capítulo I- Naturaleza de la memoria}

digitación, fraseo, etc.) de suerte que lleguen a automatizarse y pueda ocuparse así de los aspectos más críticos que demandan su atención.

Este concepto es clave para intentar dilucidar uno de los asuntos centrales en los estudios sobre memoria y ejecución musical: explicar la coexistencia de las memorias explícita e implícita en tiempo real. Durante la ejecución un músico debe coordinar la acción motora con la recuperación desde la MLP declarativa, de suerte que la memoria para lo que viene llegue a la memoria de trabajo en el momento preciso, i.e. antes de la acción motora correspondiente (Chaffin \& Logan 2006).

Las PP son representaciones conceptuales de la Música que están vinculadas a una respuesta motora, por lo que el pensamiento sobre la PP se relaciona directamente con la ejecución. Es necesario que la recuperación de las PP desde la MLP sea automatizada de manera que el costo atencional por parte del instrumentista sea mínimo. De esta forma el ejecutante puede arribar a una interpretación de calidad que conserve un cierto grado de espontaneidad y "frescura". A lo largo de la práctica el instrumentista reflexiona a partir de las PP en tanto metas expresivas, de manera que sean accesibles a la conciencia en el momento de la ejecución provocando una respuesta motora acorde. Es importante señalar que deben ser estos objetivos expresivos -y no las dificultades técnicas - los que actúen como PP. Solamente cuando las PP han logrado ser automatizadas, el instrumentista puede esperar una conexión sustancial con el mensaje musical, siendo capaz de pensar en la obra en términos expresivos. 


\section{Capítulo I- Naturaleza de la memoria}

Es posible distinguir cuatro tipos de PP organizadas de manera jerárquica como sigue:

- Estructural: en los puntos clave de la estructura musical, tales como finales y comienzo de frase o sección.

- Expresivas: estados emocionales a ser comunicados al público.

- Interpretativas: puntos en los que algún aspecto de la interpretación merece particular atención (e.g. cambios de tempo, de dinámica).

- Básicas: aspectos técnicos o estructurales que deben ser atendidos para que la ejecución siga adelante (e.g. el uso de una digitación particular para que la mano pueda seguir tocando)

La internalización de una obra supone la capacidad de recorrerla tanto por la vía del conocimiento explícito como del implícito (Bitzan, 2010). En la memorización de una obra un intérprete recurre a diversas estrategias que le permitan ir más allá de la memoria muscular (i.e. implícita y con mínimo esfuerzo consciente) y consolidar un esquema de recuperación de la información. Este esquema de recuperación es fundamental para la memoria explícita, pero no necesariamente para la motora.

Durante el aprendizaje de una obra un músico se mueve verticalmente dentro de esta estructura jerárquica atendiendo a diferentes PP. EI mayor desafío de un músico es que la práctica extendida sobre una pieza 
permita flexibilidad en el momento de la ejecución en público, sea para una mejor comunicación emocional con la audiencia o para recuperarse de cualquier imprevisto.

Las investigaciones de Chaffin y sus colegas intentan explicar la integración de los componentes explícitos e implícitos de la memoria durante la ejecución. Las PP posibilitan el control consciente de un trozo automatizado, siendo entonces la espontaneidad un subproducto que resulta de la habilidad y flexibilidad con las que el músico emplea las PP para adaptar su ejecución a los requerimientos del momento.

\subsection{Práctica extendida}

La práctica extendida es clave para disminuir el tiempo necesario en la recuperación de información desde la MLP. Normalmente el proceso de recuperación es lento, por ello el ensayo permite un incremento considerable en la velocidad de acceso a la información alojada en la MLP (Ericsson \& Kintsch, 1995 en Chaffin et al. 2002). En lugar de utilizar la partitura, el pianista puede valerse de la memoria explícita.

Sin embargo, no es posible aislar por completo los procesos de recuperación de aquel proceso de codificación que se produjo originalmente. Tulving \& Thomson (1973) establecieron la existencia de un principio de codificación específica, según el cual la recuperación exitosa de la información depende directamente de la similitud entre los 


\section{Capítulo I- Naturaleza de la memoria}

procesos de codificación y recuperación. Si la estructura opera como vía de recuperación, entonces debe ser codificada en idéntica forma durante el aprendizaje.

Recuperar no es la mera activación de lo aprendido; existen interacciones de mayor complejidad. La experiencia diaria nos muestra como en algunos casos puede ser beneficioso restablecer el contexto de la codificación ("volver a la escena del crimen" o cuando se regresa desde una habitación a otra para recordar lo que se había ido a buscar).

Recordar es el reflejo de la interacción entre ambos procesos: codificación y recuperación. Este tipo de dependencia parece aumentar cuando las pistas son más débiles (Brown \& Craik, 2000), fenómeno que puede observarse con frecuencia entre los novatos. La efectividad de la pista depende también del estado o condición mental en que la codificación tuvo lugar. Tulving \& Thomson (1973) postularon que la eficacia de una pista de recuperación de tipo discreto está determinada porque posibilita el recuerdo, en oposición a lo que ocurre con el recuerdo libre. Las investigaciones posteriores mencionadas al referirnos a las PP están en consonancia con estos hallazgos previos de la Psicología Cognitiva.

Otra característica de la recuperación es su naturaleza constructiva o reconstructiva: no se trata de una reactivación pasiva de la información; las experiencias previas y la expectativa juegan un rol clave (Brown \& Craik, 2000). En general estos procesos de reconstrucción pueden ser 


\section{Capítulo I- Naturaleza de la memoria}

útiles (es uno de los argumentos centrales para la práctica distribuida), pero podría también ser causa de errores o falsos recuerdos (Roediger \& Mcdermott, 2000).

Numerosas investigaciones empíricas han indagado el rol del agrupamiento (o "chunking") en los esquemas de codificación y recuperación. Los puntos en los cuales un ejecutante interrumpe o retoma la práctica de un fragmento musical proveen pistas sobre dichos esquemas. Se han encontrado evidencias de que se prefieren puntos críticos de la estructura (i.e. comienzos y finales de frase) al momento de segmentar una obra para la práctica (Chaffin 1997). La práctica y el repaso son útiles en tanto se organice el material en unidades bien formadas; caso contrario la repetición no facilita y hasta dificulta la tarea (Tulving, 1966).

El almacenamiento en la MLP es diferente según el nivel de pericia: los novatos operan con agrupamientos ("chunks") más pequeños y de menor complejidad que los expertos. La posibilidad de memorizar sin esfuerzos conscientes constituye un indicador de como un experto reconoce patrones y procedimientos discursivos familiares, lo que le permite operar con mayor celeridad (Chaffin et al., 2002). Sin embargo y a diferencia de otros memorizadores expertos, un instrumentista puede prescindir de la memoria explícita y valerse solo de su memoria motora y auditiva. El uso de un esquema de recuperación es imprescindible para la memoria declarativa, pero puede no serlo para la motora (Anderson 1983 en Chaffin et al, 2002) 


\section{Memoria y representaciones mentales}

El concepto de representación mental (RM) es un concepto creado para explicar cómo están constituidas algunas formas básicas de almacenamiento en la MLP. No se trata de simples copias de la realidad a la manera de fotos o imágenes visuales sino más bien de formas imperfectas que pueden conducir incluso a distorsiones de la memoria (Mitchell \& Johnson, 2000). La posibilidad de "representar" el mundo externo es anterior al procesamiento lingüístico y por ello en muchos casos no es posible su verbalización. Esto permitiría explicar que muchas representaciones que tienen que ver con la memoria musical sean difíciles de definir (Snyder, 2000) y se atribuyan al talento o a la intuición.

Interesa describir la relación que existe entre las RM y las diferencias individuales que cada ejecución supone. La ejecución musical requiere del músico la posibilidad de representar mentalmente diferentes aspectos de su tarea. La enseñanza instrumental ha tomado nota de su existencia sobre la base de la propia experiencia mucho antes de que la investigación empírica se ocupara del tema (Lehmann, 1997).

El método desarrollado por Karl Leimer y Walter Gieseking (1931) está basado en la memorización a partir de la "visualización" (que no debe confundirse con memoria visual). La memorización juega un rol central 


\section{Capítulo I- Naturaleza de la memoria}

en este método según el cual la práctica física del instrumento tiene lugar solo cuando el alumno ha internalizado la obra por vía de la práctica mental. Para ello son necesarias diversas estrategias tales como la audición interior de la obra y el análisis estructural, armónico, etc.

En sintonía con el método de Leimer y Gieseking, Edwin Gordon desarrolló el concepto de audiation (1993 en Lehmann 1997; Süberkrüb, 2006) según el cual la comprensión musical depende de la posibilidad de imaginar y oír el sonido físicamente ausente. Otros estudios (Macek, 1987 en Lehmann 1997) describen el caso de un músico que aprendió a tocar en el estilo del pianista Art Tatum partiendo de la escucha de grabaciones. Macek describe la existencia de lo que él llama "oído fotográfico" y sus hallazgos coinciden con la caracterización de la memoria experta y el uso de representaciones mentales tal como la Psicología Cognitiva lo ha descripto (Ericsson \& Kintsch, 1995 en Lehmann 1997).

Los casos planteados no pretenden sino ofrecer algunos ejemplos que permitan vislumbrar la presencia del concepto de RM en el discurso de intérpretes y pedagogos. Aunque la terminología empleada no sea la misma (no se habla de $\mathrm{RM}$ ), se reconoce la importancia que tienen diversos procesos mentales (audición, visualización, etc.) en ausencia de actividad física y se la describe siempre en términos de un don innato para la música. La posibilidad de imaginar o evocar el sonido y los medios que intervienen en su producción física es uno de los rasgos que definen la práctica mental, de la cual nos ocuparemos en el capítulo siguiente. 
Clarke (1988 en Barry \& Hallam, 2002) afirmó que los intérpretes se valen del uso de RM y propuso que necesitan comprender una obra en distintos niveles de jerarquía, es decir, proceder desde una memoria más general de la pieza hacia los detalles más mínimos. Ericsson (1997) estableció la existencia de tres tipos de representación mental observables en la ejecución musical experta.

\subsection{Representación mental del objetivo}

La representación mental del objetivo se vincula a la imagen que el músico ha bosquejado sobre como desea que suene la obra. En los novatos este tipo de RM aparece fuertemente ligada a modelos externos, ya sea que se trate del propio maestro y/o de grabaciones. La imitación es un recurso frecuentemente empleado en la enseñanza y sería incluso beneficiosa para los principiantes. Sin embargo, en niveles avanzados un intérprete es valorado en tanto sea capaz de arribar a su propia interpretación antes que por la copia de modelos.

El pianista y pedagogo Heinrich Neuhaus (1958) sugiere que ya en el primer contacto con la obra el ejecutante configura una "imagen artística" de la misma. Esta afirmación fue el disparador de una investigación para indagar en qué medida un intérprete experto se vale de la imagen global de la obra en el comienzo de su práctica (Chaffin, Imreh, Lemieux \& Chen, 2003). Esto sería una característica importante en la ejecución experta: mientras que los expertos comienzan con una imagen global de la obra, los novatos tienden a concentrarse en los 
detalles sin reparar en la imagen total (Chaffin et al 2003; Lisboa, Chaffin \& Logan, 2011).

El desarrollo de este tipo de RM parece ser dificultoso para los principiantes y los pedagogos deberían tomar nota de ello en sus clases con novatos. Zurcher (1975 en Barry \& Hallam, 2002) realizó una investigación con estudiantes noveles a los que proporcionó un casete con instrucciones, recordatorios y acompañamientos musicales y los comparó con un grupo control en el que los sujetos no recibieron ninguna grabación. La práctica con soporte de un modelo auditivo mostró ser significativamente más efectiva que la práctica tradicional. Otros estudios confirman la importancia de proporcionar modelos auditivos a los principiantes para ser usados en la práctica (Dickey, 1992; Kendall, 1990 en Barry \& Hallam 2002)

\subsection{Representación mental de la ejecución en tiempo real}

Durante la práctica el músico debe ser capaz de monitorear su ejecución a medida que transcurre (Mantel, 1987). Se ha señalado con insistencia la importancia del "escucharse a sí mismo" como una competencia esencial de todo intérprete formado (Leimer \& Gieseking, 1931). Sin embargo, la formación de este tipo de RM puede ser una tarea ardua para los novatos a causa de los diferentes niveles de consciencia involucrados en la adquisición de diversas destrezas. 


\section{Capítulo I- Naturaleza de la memoria}

La práctica supervisada por un docente ha sido consagrada por la tradición como el formato por excelencia de la clase de instrumento: mientras el alumno toca el maestro realiza correcciones, marcaciones, anotaciones en la partitura, etc. Investigaciones recientes han analizado las fortalezas y debilidades del modelo tutorial partiendo de los relatos de docentes y alumnos de un conservatorio de Inglaterra (Gaunt, 2008; 2010). Si bien se reconoce que el maestro actúa como un constante soporte, se ha observado que los estudiantes adoptan un rol pasivo en el aprendizaje y muy pocos desarrollan la posibilidad de evaluar el propio desempeño.

La RM de la propia ejecución necesita ser aprendida y las estrategias que se emplean en la clase de instrumento parecen no ser siempre las más adecuadas. Wulf \& Mornell (2008) tomaron como punto de partida investigaciones recientes sobre aprendizaje motor y analizaron su implicancia en el campo de la pedagogía musical. El éxito del feedback proporcionado por el docente (sea a partir de comentarios verbales u otras acciones, tales como cantar, marcar el ritmo, etc.) podría ser analizado partiendo de dos preguntas: con qué frecuencia y en qué momento tienen lugar. El feedback concurrente (mientras el alumno toca) suele ser una de las estrategias más corrientes, aunque hay evidencias que cuestionan su efectividad, ya que interrumpe el procesamiento de información, impide la autoevaluación y genera inestabilidad en el movimiento. 


\section{Capítulo I- Naturaleza de la memoria}

\subsection{Representación mental de los aspectos de producción}

Este tipo de RM es propia de los ejecutantes y está íntimamente ligada con las destrezas físicas que se ponen en juego al tocar cualquier instrumento. En los principiantes el aprendizaje de una obra está vinculado mayormente a aspectos físico-motores tales como digitaciones, combinación de llaves en los vientos o cambios de arco en las cuerdas. Así se establecen patrones y reglas generadoras de patrones motores. En los expertos este tipo de $\mathrm{RM}$ no es fácilmente investigable por encontrarse en niveles muy profundos y de difícil acceso a la consciencia por su grado de automatización.

Los instrumentistas expertos desarrollan por medio de la práctica extendida la habilidad de construir y usar RM que les permitan organizar y controlar aspectos relevantes de la tarea. Esto no es innato como suele creerse sino resultado del entrenamiento. Un estudio con pianistas (Lehmann, 1997) encontró evidencias del uso que hacen de las RM durante la memorización. Los buenos memorizadores son capaces de representar el material musical de una manera que pueda ser recuperada y adaptada a nuevas condiciones de la ejecución. Los sujetos que memorizan más lentamente tendieron a hacerlo nota a nota, mientras que los más rápidos lo hicieron atendiendo al movimiento de las manos o a conexiones en la música. La habilidad de representar mentalmente la música aparece reflejada tanto en la buena memorización como en la posibilidad de manipular el material memorizado, transportándolo, por 
ejemplo, a otras tonalidades (Lehmann y Ericsson, 1995 en Lehmann 1997).

Si bien el automatismo puede presentarse como una opción al uso de RM (Lehmann, 1997), la posibilidad no está exenta de numerosos riesgos que despiertan la desconfianza de los propios instrumentistas (Chaffin, 2002). Para poder recuperarse de un fallo de memoria es necesario echar mano a algún tipo de RM que haya sido debidamente practicada y por ello confiar ciegamente en el automatismo podría traer resultados catastróficos. Si bien queda mucho por conocer sobre el funcionamiento de representaciones mentales, no hay duda que son adquiridas en el contexto de la práctica deliberada y la instrucción. Uno de los desafíos centrales de la enseñanza instrumental sería conocer más sobre las RM y las actividades que se asocian con su adquisición para ampliar y mejorar así las estrategias que se emplean. 


\section{Capítulo II}

\section{NATURALEZA DE LA PRÁCTICA}

\section{Introducción}

Se presentan y describen en este capítulo los principales aportes de la investigación en relación con la práctica instrumental y su vinculación con la memoria. Dentro de la multiplicidad de enfoques existentes se han considerado contribuciones de diferentes disciplinas que se han ocupado de la temática. Desde el surgimiento de la enseñanza instrumental formal en el siglo XIX, la proliferación de métodos consistentes en ejercicios y escalas ha mostrado la predominancia de un paradigma de la práctica con fuerte énfasis en lo motor, eclipsando muchas veces la existencia de otras alternativas. Se propone a continuación un abordaje del tema a partir de una mirada holística que permita integrar los aportes de la tradición con los hallazgos de la investigación más reciente. 


\section{Conceptos generales}

La práctica ha sido definida como "la repetición de algo aprendido y el perfeccionamiento de una actividad física" (Mahlert, 2006:9). La simplicidad de la definición es aparente: el componente altamente individual y la multiplicidad de enfoques (diversas disciplinas que se han ocupado de ella) dan cuenta de un fenómeno complejo.

La importancia que tiene la práctica en el aprendizaje de una destreza es un principio difundido y aceptado en los diferentes ámbitos y disciplinas del conocimiento humano. Por ello no es casual que parte de la investigación en el tema provenga del campo de la medicina del deporte (deportología), cuyos aportes a la discusión resultan esclarecedores para entender algunos aspectos de la ejecución musical. Mientras que en el deporte se habla de entrenamiento y práctica de manera indistinta, entre los músicos el término práctica suele ser el más difundido.

En las últimas décadas la literatura sobre el tema ha crecido de manera exponencial. Es posible mencionar dos manuales publicados en las últimas dos décadas, los cuales ilustran un escenario heterogéneo en el que se ponen en juego múltiples enfoques y paradigmas. En orden de publicación, el compendio editado por Jørgensen \& Lehmann (1997) constituye el primer intento de reunir las principales teorías y hallazgos empíricos sobre la práctica en el campo de la música instrumental. Los ocho especialistas convocados 
son científicos y músicos alemanes, estadounidenses, noruegos e ingleses.

Casi una década más tarde, Mahlert (2006) editó un manual dedicado íntegramente al tema de la práctica. En más de 400 páginas divididas en 18 capítulos numerosos especialistas abordan el fenómeno desde diversos ángulos. Temas tales como la práctica mental, la didáctica, la improvisación, aspectos neurofisiológicos y corporales, la práctica en ensamble, el papel del error y la percepción auditiva dan cuenta de lo inagotable de la temática. Los autores convocados son en su mayoría pedagogos e investigadores de las principales escuelas de música alemanas. Esta elección marca un cambio radical de paradigma, con expresos cuestionamientos al método empírico y su intención de fundar una "ciencia de la práctica" (Mahlert, 2006; Gellrich, 1987). Los aportes no se agotan en estas dos publicaciones, que permiten sin embargo, visualizar un panorama tan amplio como controvertido.

\section{Estrategias de resolución de problemas}

\subsection{Práctica deliberada}

Un instrumentista invierte muchos años de su vida practicando y sin embargo no puede concluirse que ello determine progresos en el desempeño. La práctica es en sí misma una habilidad que necesita ser aprendida y desarrollada durante años de formación. En estos 
términos algunos autores han planteado el concepto de práctica formal (Sloboda et al., 1996) o deliberada (Ericsson, 1997), para designar un formato asociado a la adquisición y desarrollo de destrezas expertas en campos tan diversos como la música o el deporte. Si bien el elemento cuantitativo (en términos de horas y años) es un aspecto a considerar, no es suficiente para hablar de práctica deliberada. Ericsson (1997) ha establecido tres requisitos para que pueda ser calificada como tal: (i) que el nivel de dificultad de la tarea sea el apropiado, (ii) que exista una retroalimentación significativa y (iii) que haya oportunidad de repetir y corregir errores.

Un estudio con 40 pianistas (Gruson, 1988 en Chaffin et al, 2002) reveló diferencias notorias en la práctica según el nivel de pericia. La principal diferencia es que los más experimentados fueron capaces de operar con segmentos de mayor extensión y pensar la obra en términos más globales. Se observó que en el tratamiento de los errores los novatos tienden a corregir a partir de la repetición de la nota equivocada y no en secciones o fragmentos. Una segunda diferencia fue que los expertos pueden practicar de manera más intensa y con menor número de interrupciones. El tercer aspecto de la práctica que recibe el impacto de la experiencia aparece vinculado con la autoevaluación: los comentarios revelaron componentes metacognitivos entre los estudiantes más avanzados.

La experiencia es un factor crucial en la reducción del tiempo de práctica. El mantenimiento de una destreza aprendida demanda 


\section{Capítulo Il- Naturaleza de la práctica}

menos tiempo que el que fue necesario para su adquisición, y ello explica que los músicos más experimentados reduzcan considerablemente el monto de tiempo que invierten (Lehmann, 1997; Wessel, 2012).

Mientras que algunas investigaciones han indagado en aspectos cuantitativos de la práctica como determinante de la pericia (número de horas en distintos niveles, edades e instrumentos), estudios más recientes se han ocupado de las estrategias que se ponen en juego. Susan Hallam (2001) llevó adelante un estudio de tipo exploratorio con 55 instrumentistas de cuerda cuyas edades oscilaban entre los 6 y 18 años, desde principiantes a aspirantes de escuelas de música. Los sujetos fueron grabados por un período de 10 minutos mientras practicaban una pieza breve adecuada a su nivel. Las grabaciones fueron analizadas por dos jurados independientes entre sí. Se encontró evidencia de que la efectividad de las estrategias depende de esquemas auditivos apropiados, los cuales permiten evaluar el progreso y corregir errores. El empleo de estas estrategias estaría íntimamente relacionado con el nivel de pericia del sujeto. La investigación establece una secuencia que estaría relacionada con la pericia antes que con la edad. Dicho desarrollo está vinculado estrechamente con el reconocimiento de los errores y la posibilidad de estimar dificultades. Los más novatos simplemente repitieron la obra de principio a fin. En el nivel siguiente los errores son identificados y corregidos, recurriendo luego al ensayo de pequeñas secciones donde el fallo está contenido. Por último, los expertos 


\section{Capítulo Il- Naturaleza de la práctica}

adoptan estrategias para identificar secciones complejas y realizar una práctica concentrada sobre las mismas.

La posibilidad de adquirir esquemas auditivos relevantes es crucial en el avance por estas etapas y el solo uso de estrategias metacognitivas sería insuficiente. Los maestros deberían proporcionar oportunidades para la formación de estos esquemas auditivos, que muchas veces son aprendidos sin esfuerzo consciente por vía de la enculturación. Otras investigaciones han confirmado la importancia de la familiaridad con un estilo musical como condicionante en tareas tales como la lectura a primera vista (Lehmann \& McArthur, 2002).

En los niveles más bajos fue posible observar que los sujetos atendieron en primer orden a la altura correcta de las notas para ocuparse luego del ritmo. Si bien este hallazgo no puede generalizarse a todos los instrumentos (los sujetos en el estudio son ejecutantes de cuerdas), se observa una tendencia generalizada entre los novatos a practicar atendiendo a un aspecto en desmedro de otros. El foco de la atención se asemejaría a un "reflector" que ilumina algunos estímulos y los vuelve conscientes, mientras otros se van desvaneciendo hasta la oscuridad (Altenmüller, 2006). En el modelo de práctica de atención rotativa propuesto por Gerhard Mantel (1987; 2001), resulta crucial la interacción entre repetición y desplazamiento del foco de atención. Los aspectos centrales de la práctica están distribuidos en una roseta o círculo (agógica, 


\section{Capítulo II- Naturaleza de la práctica}

dinámica, afinación, ritmo, fraseo, articulación) y deben ser ejercitados de manera rotativa.

En los resultados del estudio de Hallam (2001), fue posible advertir una tendencia de los maestros a creer que los alumnos implementan de manera consistente en su práctica aquello que han aprendido durante la clase, circunstancia que los relatos de los propios estudiantes confirmaron; la evidencia empírica mostró en cambio, que los alumnos no manejaban las estrategias de manera consistente.

De lo expuesto pueden derivarse dos implicancias vinculadas a la práctica y su enseñanza: (i) es fundamental que el foco atencional sea dinámico, evitando el monopolio de algunos aspectos y (ii) que las estrategias de práctica lleguen a ser parte activa de la rutina de trabajo del estudiante, incorporándose de manera natural y fluida al bagaje de herramientas empleadas a diario.

\subsection{Práctica en flujo}

La motivación es otro de los aspectos que la investigación sobre el tema ha indagado a lo largo de las últimas décadas. La ejecución experta estaría acompañada por un estado subjetivo óptimo en el que la fluidez y dinamismo en la tarea permite una suerte de "estado de trance", experiencias que han sido conceptualizadas por la 
psicología como experiencias de flujo (Csikszentmihalyi, 1990). La investigación cualitativa basada en relatos de los sujetos ha establecido nueve características de la experiencia de flujo:

(i) Equilibrio entre niveles de desafío y habilidad: la tarea no es demasiado fácil pero tampoco demasiado compleja, de lo contrario aparecerán sensaciones de aburrimiento o frustración.

(ii) Fusión de acción y conciencia: las acciones parecen automáticas o con bajo costo atencional.

(iii) Objetivos claros.

(iv) Retroalimentación no ambigua.

(v) Alto nivel de concentración en la actividad.

(vi) Sensación de control de la tarea.

(vii) Pérdida del autoconocimiento: la autorreflexión y el temor a la evaluación social están ausentes.

(viii) Transformación del tiempo: el tiempo parece transcurrir más rápido o lento que lo habitual. 


\section{Capítulo Il- Naturaleza de la práctica}

(ix) Experiencia autotélica: la actividad es intrínsecamente gratificante y el esfuerzo que demanda se vuelve imperceptible.

Las experiencias de flujo han sido estudiadas por la neurofisiología y aplicadas al campo de la enseñanza instrumental. Andreas Burzik (2006) ha enunciado cuatro principios que rigen la aplicación de estas experiencias en la práctica instrumental:

(i) El contacto con el instrumento: los puntos de contacto (labios, dedos) juegan un rol fundamental en la transmisión de la fuerza del ejecutante a su instrumento, la cual transcurre sin esfuerzos y es habitual que los músicos hablen de una extensión del propio cuerpo para describir ese contacto.

(ii) El desarrollo de una conciencia tímbrica, es decir una sensibilización a los armónicos que se producen como resultado del toque (la forma en que el pianista ataca la tecla, el contacto del arco con la cuerda en el caso de los cuerdistas).

(iii) La sensación de no esfuerzo: cada tarea es experimentada como ausencia de esfuerzo. Un ejemplo sería cuando al manipular el tempo de un pasaje o sección no sobreviene un agarrotamiento o contracción muscular como resultado de la sobrecarga en el sistema. 
(iv) Una relación lúdica con el material: el primer contacto debe servir para establecer lo descripto en los tres principios anteriores, sin la presión de que la ejecución sea "correcta" ni la de una versión ideal (a la cual se arriba gradualmente a lo largo del proceso). La sensación de no esfuerzo debe estar siempre en el centro de la práctica instrumental.

\subsection{Práctica masiva vs. práctica distribuida}

La organización y distribución de tareas dentro de la práctica es otra de las temáticas de interés para la investigación, cuyos hallazgos plantean nuevos desafíos a las estrategias que se emplean habitualmente.

El papel que juega la repetición es central e inherente a la práctica. Un instrumentista selecciona aquellas partes de una obra que necesitan mayor trabajo y la manera en que opera sobre esta selección está determinada por la pericia (Jørgensen, 2004). Para los principiantes un número de repeticiones sin error sería indicador de éxito y de que pueden continuar con otro fragmento. Sin embargo a partir de nuevas indagaciones la investigación ha cuestionado la eficacia de esta manera de practicar. 
El concepto de interferencia contextual explica la incidencia de las interrupciones y permite plantear una nueva categorización de la práctica: por un lado la práctica distribuida (con un número elevado de interferencias entre repeticiones), en oposición a la práctica masiva (en la que el número de interrupciones es escaso o considerablemente menor). Un estudio de Shea \& Morgan (1979 en Wulf \& Mornell, 2008) mostró que aunque la práctica masiva fue más fácil (dado que la repetición evita cambiar continuamente de tarea), quienes habían practicado de manera distribuida obtenían un rendimiento claramente superior en relación a sus pares. Esto es particularmente observable cuando se comparan los efectos de ambos tipos de práctica frente a tareas de retención o transferencia: la desventaja inicial de la práctica distribuida se vuelve luego una ventaja en el aprendizaje.

Existen al menos dos hipótesis que permitirían explicar el efecto de interferencia contextual en el aprendizaje psicomotor. Por un lado se postula una hipótesis de elaboración, según la cual la práctica distribuida promovería un uso múltiple y variado de las estrategias de procesamiento, generando así representaciones mentales más elaboradas y estables. La distribución de actividades posibilitaría la comparación entre las distintas tareas alojadas en la MCP, lo cual no es posible en la práctica masiva. Otra explicación viene dada por la hipótesis de la reconstrucción: al introducir interferencias en la práctica distribuida, se originan olvidos parciales entre los períodos de trabajo que obligan a la reconstrucción repetida del programa 
motor. En la práctica masiva esto no sería necesario ya que el programa motor opera desde la MCP.

Estos hallazgos resultan esclarecedores en la práctica de la enseñanza y permiten explicar un error frecuente: la ilusión de que un aprendizaje ha tenido lugar, cuando en realidad se está frente a un almacenamiento temporal, ya sea luego de varias repeticiones sin errores o por la ejecución correcta tras las indicaciones del maestro (Wulf \& Mornell, 2008). Este éxito efímero no es indicador de que exista una retención en la MLP, ni de una representación mental accesible y transferible a otros contextos (sea para la propia obra en el futuro o para otras composiciones).

No se han registrado hasta el momento investigaciones que examinen el rol de la interferencia contextual en músicos, pero se han encontrado indicios de que la práctica distribuida podría no ser efectiva frente a tareas complejas o cuando el ejecutante es menos experimentado (Wulf \& Shea, 2002). La eficacia de la práctica distribuida sería viable frente a tareas más sencillas y cuando se trate de mantener patrones motores aprendidos.

La neurociencia ha aportado evidencias que permiten afirmar que la práctica masiva podría perjudicar y generar retrocesos en el rendimiento. La repetición conduce a la disminución de la atención y a un consecuente debilitamiento de las representaciones mentales. Altenmüller (2006) ha denominado a este fenómeno efecto Penélope, en el cual la práctica masiva opera de manera perjudicial sobre la 
Capítulo II- Naturaleza de la práctica

codificación en la memoria. Aunque las explicaciones de este fenómeno son materia de investigación, se cree que al producirse el cansancio de los grupos musculares intervinientes, entrarían en juego otros músculos no ejercitados. Esto conllevaría no sólo una pérdida en términos de coordinación, sino también el almacenamiento paralelo en la memoria de un programa motor menos eficaz.

\section{Estrategias de codificación}

\subsection{Práctica mental}

"Cuando me siento en un café en París rodeado de gente, no estoy indiferente. Reviso alguna sonata en mi cabeza y descubro cosas nuevas todo el tiempo"

Arthur Rubinstein (1887-1982)

La práctica mental (P.M.) implica el ensayo cognitivo imaginado de una destreza sin empleo de actividades musculares o motoras (Barry \& Hallam 2002). Este tipo de práctica que es común en directores no siempre forma parte de las estrategias empleadas por el resto de los músicos en sus rutinas de estudio. Durante la PM un intérprete debe prescindir inevitablemente de las memorias implícitas que activan los programas motores y recurrir a la información almacenada por vía de la memoria explícita (Bitzan, 2010). 
Considerando el momento de su empleo, Oxendine (1984, en Barry \& Hallam, 2002) postuló tres tipos de PM: (i) la que tiene lugar inmediatamente antes, durante o después de la ejecución, (ii) la que se lleva a cabo entre los distintos períodos de práctica física y (iii) la toma de decisiones y planificación de la actividad, que tiene lugar durante (o entre) los períodos de práctica física.

Los registros anecdóticos de reconocidos intérpretes dan cuenta de este tipo de práctica a lo largo de la historia: Franz Liszt habría interpretado una obra de su discípulo Félix Draeseke sin haberla tocado al piano antes y con solo haberla leído silenciosamente. Hans von Bülow estudió así mucho repertorio durante sus viajes. Igualmente Walter Gieseking o Arthur Rubinstein quien relató que en un viaje en ómnibus haber estudiado en su imaginación pasajes y digitaciones complicados de las Variations symphoniques de César Franck para tocar inmediatamente después la obra de memoria (Bitzan, 2010). No se trata de meros registros de una práctica inusual o perimida. Los pianistas Paul Badura Skoda, Pierre Laurent Aimard o el cellista Jean-Guires Queyras han relatado experiencias similares sobre sus rutinas de trabajo en el aprendizaje de nuevas obras (Wessel, 2012).

La neurociencia ha aportado evidencias de que la imaginación del movimiento produce el mismo tipo de actividad muscular que el movimiento real (Connolly \& Williamon, 2004). Este fenómeno fue estudiado ya en el siglo XIX por el médico inglés William Charpenter, 
quien acuñó el término "efecto ideomotor", conocido actualmente como efecto Carpenter (Berg, 2010).

Las primeras referencias a la PM en la pedagogía musical deben rastrearse en la primera mitad del siglo XX. Una de ellas fue Margit Varró en su libro Das lebendige Klavierunterricht [La clase de piano viva] (1929). Para Varró el estudio de una obra se divide en dos partes de igual importancia: una parte mental y otra de ejercitación en el instrumento.

Poco tiempo después Karl Leimer y su discípulo Walter Gieseking (1931) sostuvieron que la práctica física debe tener lugar solamente cuando el alumno ha memorizado la obra por medio de la lectura y la reflexión sobre la partitura sin recurrir al empleo del instrumento. El período de tiempo en que es posible realizar esta práctica sin interrupción oscila según Leimer \& Gieseking, entre los 20 y 30 minutos.

Entre los pedagogos actuales que se han ocupado de la PM se encuentra el pianista Christian Pohl (2006), quien estructura la PM en dos fases: una fase de descripción sistemática (similar a la propuesta por Leimer y Gieseking) y una fase de reducción estructural del texto musical. Un aspecto crucial en el método de Pohl es la técnica de verbalización de los puntos clave de la obra, concepto que podría asemejarse al de las PC acuñado por Chaffin (véase capítulo I). La información proporcionada por el análisis permite el almacenamiento de un conocimiento explícito. Aunque el 


\section{Capítulo Il- Naturaleza de la práctica}

autor no se proponga describir una técnica para la memorización, el trabajo desplegado involucra el ensayo de diferentes tipos de representación mental del texto musical, cruciales para el almacenamiento y la recuperación de la información alojada en la memoria. La metodología propuesta por Pohl está centrada en el trabajo sobre el texto musical y de ninguna manera agota las posibilidades que la PM presenta en relación a las demás facetas de la ejecución.

La efectividad de la PM está planteada en una serie de principios que surgen de la revisión de la literatura existente (Weinberg, 1982 en Barry \& Hallam, 2002):

- La existencia de alguna experiencia previa en la tarea (o en alguna semejante).

- La posibilidad de verbalizar la tarea: la interdependencia de los lenguajes corporal y hablado abren un nuevo espacio para la práctica y la pedagogía de la performance (Mantel, 2006).

- El uso de técnicas apropiadas de concentración enfocada y visualización.

- El uso combinado de PM y práctica física. 
- El tiempo de aplicación: los períodos de uso de la PM son ostensiblemente menores a los de la práctica física debido al alto costo atencional requerido.

- La posibilidad de imaginar respuestas musculares cuya concreción real se materializa en la práctica física.

Gerhard Mantel (2001) asegura que todo lo que puede ser practicado de manera "real" puede serlo también en forma mental, ya que los principios son los mismos. De esta manera, la PM posibilitaría una práctica sin sobreexigencia de los grupos musculares involucrados en la ejecución y las posibles lesiones que trae aparejadas. La PM permite además la activación y refinamiento de las representaciones mentales involucradas en la ejecución. Se ha estimado que el éxito de la PM es más acentuado en las fases más avanzadas de la práctica, cuando las representaciones mentales son más estables.

A pesar del consenso existente sobre los beneficios de la PM, su aplicación sigue siendo escasa o poco sistemática. Una investigación (Haddon, 2007) se propuso explorar el desarrollo del aprendizaje en alumnos y profesores músicos de la Universidad de Nueva York a través de cuestionarios. En ellos fue posible observar que la PM apareció como la menos popular, aunque los reportes verbales dieron cuenta del uso consciente de algún tipo de representación mental. Otra investigación (Davidson, Kelly et al 2012) mostró que aunque los músicos profesionales conocen la PM la evidencia de su uso es más bien escasa. Aun cuando los estudiantes pueden conocer 
Capítulo II- Naturaleza de la práctica

algunos enfoques o estrategias no siempre saben cómo implementarlas.

\subsection{Procesamiento de la información}

La observación de los puntos de la partitura en los que el ejecutante se detiene y/o desde los cuales inicia su práctica permite obtener información relevante sobre cómo es codificada la información. El conocimiento de la estructura juega un rol clave en el aprendizaje de una obra y un correcto agrupamiento es requisito ineludible para que la codificación sea significativa. En este caso los límites de secciones funcionan como pistas para la recuperación desde la MLP.

Un instrumentista no procesa la información en términos de un agrupamiento estrictamente formal. Existen paquetes ("chunks") de tipo motor, los cuales no pocas veces determinan contradicciones con la estructura de la obra. Un pianista ha ensayado durante años numerosos patrones musculares (en ejercicios y/o estudios técnicos), cuyo reconocimiento -sea o no consciente- facilita el aprendizaje de una obra nueva. La práctica focalizará aquellos puntos conflictivos que determinan desviaciones de los patrones estandarizados.

La observación y los comentarios de una pianista memorizando el Presto del Concierto Italiano de Bach (Chaffin et al. 2002) 


\section{Capítulo Il- Naturaleza de la práctica}

permitieron advertir al menos dos clases de desviaciones: la primera vinculada a un aspecto puramente motor (e.g. la dificultad de reconocer en la música de Bach patrones de digitación constantes) y la segunda, relacionada con aquellos puntos de la estructura donde la repetición plantea divergencias que podrían conducir a otras secciones de la obra. En la recapitulación de una sonata clásica por ejemplo, una nota puede poner en juego un patrón motor que inicie una modulación indeseada respecto de la dominante y 'deje' al instrumentista varias páginas más atrás. Estos 'interruptores' pueden jugar una mala pasada por lo que es necesario un monitoreo consciente que atienda a la estructura total de la pieza para evitar caer en la trampa. Lo interesante de estos interruptores es que constituyen un punto de puja entre los componentes explícitos e implícitos de la memoria en la ejecución musical.

Mishra (2002, 2005, 2011) observó cómo los músicos procesan la información durante la práctica e identificó el empleo de cuatro tipos de estrategias: segmentaria, holística, seriada y aditiva. La diferencia radica en el modo en que el nuevo material se agrega al existente.

\subsubsection{Holística y segmentaria.}

Si bien son tolerables algunos retrocesos o lapsus de memoria, cuando un músico se vale de una estrategia holística repite la pieza de principio a fin. La segmentación, en cambio, supone la práctica en 


\section{Capítulo Il- Naturaleza de la práctica}

trozos, de suerte que se focalice en secciones aisladas de la pieza. La eficacia de ambas estrategias ha sido cotejada en diversas investigaciones $y$ los resultados no han arrojado conclusiones unívocas. Mientras que algunos estudios encontraron más eficaz el procesamiento holístico (Clapp, 1924; Eberly, 1921 en Mishra 2011), otros hallaron un mejor rendimiento en el procesamiento segmentario (O'Brien 1943 en Mishra 2011). Una tercera posición encontró ambas opciones igualmente efectivas (Rubin-Rabson, 1940 en Mishra 2011).

Es posible que un enfoque de tipo holístico sea más adecuado al momento de abordar una obra más sencilla, mientras que frente a piezas de mayor complejidad sea más apropiado segmentar la información. Aparecen en este punto dos dificultades: la primera es delimitar qué constituye 'todo' y 'parte' (ocho compases parece ser una extensión preferida, aunque podría ser considerablemente breve en una obra más extensa). La segunda cuestión es determinar cuál de las estrategias resulta más efectiva para la memorización, aunque el uso de estrategias segmentarias parece ser preferido por los expertos. El concepto de 'totalidad' en el procesamiento holístico podría referirse también a secciones completas en obras de mayor extensión.

El uso de un tipo de estrategia de procesamiento es flexible; permite la combinación y alternancia con las demás (Chaffin et al., 2002; Hallam, 1997; Williamon, 1999). 
Chaffin et al (2002) realizan una diferenciación entre dos tipos de práctica: uno consistente en "tocar de corrido" a lo largo de un segmento más o menos prolongado y el otro referido a un "trabajo localizado" sobre fragmentos más pequeños. Estos trozos son repetidos con el objetivo de resolver problemas puntuales y establecer una memoria de tipo muscular que garantice la fluidez del trozo. Tocar "de corrido" implica abarcar secciones más extensas de una obra con un mínimo de interrupciones. Empleada en esta forma, la segmentación cumple básicamente tres funciones: localizar pasajes que requieran especial trabajo, practicar transiciones entre secciones y por último poner en un contexto más global las decisiones interpretativas. Este tipo de abordaje debiera ser alentado e incorporado a la práctica ya desde los primeros momentos de estudio de una obra (Mantel, 2001).

\subsubsection{Seriada y Aditiva}

Los tipos de estrategia descriptos en el apartado anterior han sido objeto de numerosas investigaciones, algo que no ha ocurrido con el procesamiento serial ni aditivo. Ambos enfoques parten de la idea de segmentar el material, pero difieren en la manera en que esos segmentos se combinan.

Un instrumentista pone en juego una estrategia aditiva cuando partiendo de un pequeño trozo avanza ampliándolo de manera 
sistemática hasta abarcar la pieza en su totalidad. A diferencia del procesamiento segmentario, aquí no se hace hincapié en la práctica de fragmentos aislados que se unen posteriormente, sino que se refuerza de manera continua el material ya aprendido que se suma al existente.

Es habitual entre los novatos recurrir a una estrategia de procesamiento seriado, que puede observarse cuando practican una obra desde el comienzo y retoman desde el inicio cuando se produce un error. El recorte que se realiza al aplicar esta estrategia está marcado por un énfasis desproporcionado en el error o falla de memoria, que no permite determinar causas ni tampoco contextualizar el problema en un nivel más abarcativo de la estructura. Por esta razón la memorización es para los principiantes un subproducto de la mera repetición. Aunque no se han investigado empíricamente sus implicancias, el rechazo a esta estrategia es unánime entre pedagogos y profesionales. Los maestros debieran estar alertas y proponer actividades alternativas toda vez que adviertan que sus alumnos practican de esta manera (Mishra, 2011), de suerte que las repeticiones sean significativas. En relación con la incidencia del procesamiento seriado en la memorización para la ejecución, se encontraron evidencias que sugieren que tal como sucede en la esfera verbal, la memoria musical estaría determinada por la posición serial. En el caso del piano y otros instrumentos polifónicos la tarea de recuperación reviste mayor complejidad en tanto involucra una dimensión horizontal y otra vertical (Mishra 2010). 
Los efectos de primacía y recencia juegan un papel clave para analizar el procesamiento de tipo seriado: en interacción con la estructura musical la memorización en el comienzo de una melodía fue encontrada ostensiblemente mayor en el comienzo y decreció hacia el final (Chaffin et al 2002; Koh \& Cuddy 2000 en Mishra 2005). Mientras que el efecto de primacía jugaría un rol clave en la memoria musical, no se han encontrado mayores evidencias de efectos de recencia. Los hallazgos coinciden con los estudios sobre estos efectos en otros campos de la memoria experta.

La efectividad de estas cuatro estrategias de procesamiento en la memorización ha sido objeto de investigaciones recientes (Mishra, 2011). A una muestra conformada por 40 instrumentistas de viento de nivel universitario se solicitó que memorizaran un fragmento de 16 compases. Se consideraron dos condiciones: el grado de rapidez con que pudo ser codificada la notación musical (eficiencia) y el número de errores cometidos en la ejecución posterior (estabilidad). Se concluyó que el empleo de la estrategia holística fue significativamente más eficaz que las de tipo segmentada y seriada. Segmentar una pieza (sobre todo en fragmentos muy pequeños) podría dificultar el desarrollo de una representación mental que permita la comprensión estructural de la obra y además introducir patrones motores que interfieren en el flujo kinestésico del movimiento. 


\subsection{Práctica analítica}

La práctica supone la puesta en acto de una decisión surgida del análisis, cualquiera sea el grado de sistematicidad o intuición que lo propicie (Meyer, 1973). La interpretación musical involucra la toma permanente de decisiones en relación al lugar que ocupan determinadas funciones en un contexto musical y la manera en que deben ser proyectadas (Rink, 2002).

Esto no supone que las decisiones interpretativas emanadas del análisis sean únicas y excluyentes (Schmalfeldt, 1985). La interpretación musical en tanto actividad co-creadora está sustentada en un profundo análisis de los aspectos que la obra musical presenta (Berry, 1989; Narmour, 1988), lo cual trae aparejado valiosos aportes a las diferentes áreas de la ejecución, incluida la memorización (Chaffin \& Imreh, 1997; Snyder, 2000; Williamon, 1999).

El análisis es una herramienta que permite reconocer y relacionar patrones insertos en la estructura de una obra. Algunos autores (Hallam, 1997 b) han intentado dilucidar el rol que tiene en las tareas orientadas a la memorización: en los expertos, este estilo de aprendizaje operaría como un marco contenedor en el que la memoria motora se desenvuelve.

El análisis puede ser incorporado ya en las etapas más tempranas de la formación de un músico, puesto que constituye una herramienta 


\section{Capítulo Il- Naturaleza de la práctica}

imprescindible en la conformación de representaciones mentales más abarcativas y estables. Existe consenso en que es una estrategia preferida por los expertos durante la práctica por oposición a los novatos (Hallam, 1997b; Williamon \& Valentine, 2002). Una representación mental de tipo conceptual permite un mayor control y el instrumentista puede saber "dónde está" en la estructura musical de la pieza (Chaffin, 1997) y operar de acuerdo a ese conocimiento.

Los ejecutantes que se valen de un procesamiento segmentativo del material evidencian un uso más ostensible de la estructura musical estableciendo relaciones entre fragmentos practicados y la forma de la obra (Chaffin et al. 2002; Williamon \& Valentine, 2002). En otros casos la segmentación podría obedecer a características físicas de la partitura impresa (e.g. vueltas de página) Sin embargo, la paginación de una obra no responden a cuestiones musicales sino a una decisión editorial (Chaffin et al, 2002).

\section{Estrategias de recuperación}

Jennifer Mishra (2005) describe un modelo de memorización para la ejecución que comprende tres etapas: previa, de la práctica propiamente dicha y de afianzamiento. La memorización es un proceso complejo y este modelo no pretende ser algorítmico ni secuencial: la flexibilidad de las etapas y de sus subdivisiones están 


\section{Capítulo Il- Naturaleza de la práctica}

directamente relacionadas con cada sujeto. El modelo consta además de una instancia preliminar vinculada a la enculturación y la experiencia previa que resultan esenciales al proceso de memorización. Tradicionalmente se han configurado cuatro estrategias de memorización (auditiva, visual, kinestésica y analítica) que este modelo agrupa en dos estilos de aprendizaje: el sensorial (auditivo, visual y kinestésico) y el analítico. Por último se describen cuatro vías de procesamiento para explicar de qué manera el intérprete segmenta el material durante las sesiones de práctica.

\subsection{Enculturación y experiencia.}

La ejecución experta de una obra o trozo musical es el resultado de la interacción entre el conocimiento de la obra practicada y un extenso cúmulo de experiencias previas (Sloboda, 1985). Dichas experiencias como oyente o ejecutante, juegan un rol clave en la familiarización con los diversos estilos musicales (Meyer, 1989). Este conocimiento tácito se adquiere por la experiencia antes que por la vía de la instrucción formal y la familiaridad con el estilo es un factor determinante en tareas como la lectura a primera vista (Thompson \& Lehmann, 2004) permitiendo una recuperación más veloz desde la MLP.

Existen evidencias en la memorización experta de que los sujetos poseen un vasto dominio previo que posibilita una mayor eficiencia: 


\section{Capítulo Il- Naturaleza de la práctica}

diferentes experimentos con cadenas de dígitos, posiciones de ajedrez y notas musicales mostraron una mayor eficiencia de los expertos sobre los novatos (Chase \& Simon, 1973; Doling, 1982; Ericsson \& Chase, 1982; Ericsson \& Lehman, 1996, en Mishra, 2005).

La importancia de la enculturación se pone de manifiesto en las investigaciones que han empleado música tonal y atonal. En la cultura occidental el grado de exposición al lenguaje tonal y sus patrones es muchísimo mayor y en consecuencia los resultados reflejan una mayor facilidad para memorizar ejemplos tonales que atonales (Nuki, 1984: Sloboda, Hermelin \& O'Connor, 1985 en Mishra, 2005) o modales (Oura \& Hatano, 1988, en Mishra 2005). La dificultad para reconocer patrones en estos lenguajes trae como consecuencia una mayor demanda de tiempo para la memorización (Miklaszewski, 1995; Nuki, 1984 en Mishra, 2005).

\subsection{Etapa previa}

La práctica de una obra musical suele iniciarse con actividades tendientes a conocer la pieza en su totalidad. Este primer acercamiento involucrando el uso de una estrategia de tipo holística está extensamente documentado en la literatura pedagógica (Neuhaus, 1958), en testimonios de instrumentistas profesionales (Wessel, 2012) y en diversas investigaciones empíricas (Chaffin et al, 2003; Hallam, 1997a/b/c). 
Durante esta etapa se establece el tempo de la pieza, se identifican los pasajes más complicados y se tiene un vistazo global de la obra sea a través de la audición, el examen de la partitura lejos del instrumento (basado en todos o en algunos componentes musicales) y la ejecución cantando o tocando la obra en su totalidad. No debe confundirse este tipo de ejecución con lo que habitualmente se conoce como lectura a primera vista, es decir tocar por primera vez desde la partitura sin o con un mínimo ensayo (Lehmann \& McArthur, 2002; Thompson \& Lehmann, 2004). Las diferencias con la lectura a primera vista radican en el número de repeticiones necesarias para adquirir una impresión holística de la pieza y en la posibilidad de corregir errores (mientras que en la repentización se privilegia la continuidad y estabilidad en el tempo).

El ejecutante puede valerse de uno de los métodos descriptos o de una combinación de ellos siendo el orden aleatorio. Por ejemplo: escuchar grabaciones suele ser una actividad habitual para algunos músicos antes de embarcarse en el examen de la partitura o de la ejecución; otros instrumentistas preferirán escuchar una grabación siguiendo la partitura. La ejecución global de la pieza parece ser el método preferido y por ello es poco habitual que se omita. No sería éste el caso para los defensores más radicalizados de la práctica mental desde el comienzo (como en el método Leimer-Gieseking), los cuales rechazan toda práctica física previa a la memorización de la obra. 


\section{Capítulo Il- Naturaleza de la práctica}

Puede ocurrir que esta etapa sea omitida cuando el intérprete decide encarar directamente el estudio técnico de la obra, en cuyo caso la estructura irá emergiendo a medida que se practica.

La eficacia de estos métodos para la memorización es un área a explorar y las investigaciones existentes han arribado a resultados controvertidos. No se ha determinado cuál es el grado de preferencia en el uso simple o combinado de los métodos, la frecuencia con la cual la etapa previa es omitida en la práctica o la eficacia que el examen de la partitura tiene a los fines de la memorización: mientras algunos estudios lo consideran positivo (Lo, 1976; Ross, 1964; RubinRabson, 1940a; Rubin-Rabson, 1941b todos en Mishra 2005), otros muestran lo contrario (Jones, 1990; Reynolds, 1975; Shockley, 1980 en Mishra, 2005). Tampoco se encontraron evidencias de que la escucha (acompañada o no del examen de la partitura) optimizara la memorización (Buckner, 1970; Rubin-Rabson, 1937; Schlabach, 1975, en Mishra 2005).

\subsection{Etapa de la práctica}

Esta etapa puede subdividirse en la práctica basada en la notación y la práctica de la memorización consciente. Las actividades durante esta etapa ponen especial énfasis en la ejecución de la partitura escrita. Las características individuales del ejecutante (pericia, familiaridad con la obra, metas interpretativas) y de la obra operan 


\section{Capítulo Il- Naturaleza de la práctica}

como factores determinantes para la cantidad de tiempo que se invierte en la tarea. En aquellos casos en que una obra no presenta mayores retos técnicos o es aprendida por repetición esta etapa podría omitirse. Durante la práctica con partitura sea de manera permanente o esporádica, el ejecutante desarrolla una memoria incidental para la obra y para estímulos negativos. Varios autores han indagado sobre el posicionamiento y las estrategias que ha tenido tradicionalmente la sesión o lección de instrumento frente al "error" (ver Wulf \& Mornell, 2008; Röbke, 2006; Mantel, 2001). Esta y otras condiciones externas que parecen ajenas a la ejecución se imprimen en la memoria como pistas inconscientes que pueden poner en peligro la ejecución en situaciones futuras. La incidencia que el espacio ambiental tiene en la memorización (cuando se altera - se cambia de lugar la recuperación se vería afectada y podrían producirse fallas de memoria) no ha sido exhaustivamente investigada como para arribar a conclusiones definitivas (Mishra, 2007).

Cuando el instrumentista es capaz de tocar con el auxilio de la partitura está en condiciones de ocuparse de la memorización consciente de la música. Sin embargo, tanto novatos como expertos empiezan a memorizar desde los inicios del aprendizaje, aunque no sea de manera deliberada (Hallam, 1997b). Aun cuando la memorización no sea el objetivo principal de la práctica, existe consenso en que los instrumentistas son capaces de recuperar información, en tanto desarrollan una memoria inconsciente o automática. Lehmann \& Ericcson (1998) encontraron evidencias del 
Capítulo II- Naturaleza de la práctica

uso de esta memoria incidental "cubriendo" fragmentos de la partitura: entre el $30 \%$ y el $88 \%$ de las notas ocultas pudieron ser recuperadas luego de 4 ensayos. Otras evidencias han sido proporcionadas por la observación del comportamiento del instrumentista en el momento de cambio de página de la obra.

La memorización que se desarrolla durante la práctica con partitura requiere, sin embargo, el empleo técnicas conscientes de memorización. Hallam (1997b) entrevistó a 22 músicos profesionales y a 55 novatos para saber cómo abordaban la memorización. Las posibilidades dependen de las características del material a memorizar y de las preferencias individuales. Las estrategias cambian a medida que la pericia se desarrolla; los más expertos hacen esfuerzos deliberados por emplear estrategias analíticas y de comprensión de la estructura a fines de evitar fallas en pasajes similares, observación compartida por Roger Chaffin y sus colegas (2002).

\subsection{Estilos de aprendizaje sensorial}

La tradición pedagógica coincide desde hace un siglo en la existencia de tres tipos de memoria de tipo sensorial que los instrumentistas emplean: auditiva, visual y kinestésica o motora. Los testimonios de ejecutantes y educadores constituyen un valioso aporte que dista de ser sistemático o unívoco (Bitzan 2010; Matthay, 1926), aun cuando 


\section{Capítulo II- Naturaleza de la práctica}

la investigación empírica reciente ha confirmado algunas presunciones. Estos tipos de memorización pueden combinarse y la flexibilidad en su uso y no dependieron en todos los casos del nivel de pericia (Hallam, 1995, 1997b; Nielsen 1997). El debate en la literatura pedagógica o en los testimonios de los propios instrumentistas muestra que no existe acuerdo sobre cuál de estos tipos de memoria es más efectivo y si la combinación de ellos se traduce en una mayor seguridad en la memorización. La investigación sobre el tema se ha llevado a cabo fundamentalmente por vía de la introspección y/o entrevistas (Chaffin et al 2002).

La memoria auditiva permite escuchar una obra sin disponer de una fuente sonora o de pistas provistas por la partitura. Este tipo de memoria es crucial en músicos que no se valen de la partitura y aprenden escuchando e imitando lo que escuchan (e.g. jazz). Algunos autores han hablado de un "oído fotográfico" (Macek, 1987, en Ginsborg 2004) que permitiría la recuperación detallada de música compleja. La presente tesis se ocupa de los instrumentistas enrolados en la tradición occidental en la cual el estudio de una obra se realiza con partitura. En este contexto la memoria auditiva es casi automática y se da por sentada, aunque sería objeto de atención cuando un intérprete tiene que aprender música en la que es evidente la ausencia de patrones predecibles auditivamente (e.g. música atonal o polifónica) (Chaffin et al 2002).

La memoria visual es empleada solo por algunos intérpretes (Chaffin et al 2002), quienes desarrollan representaciones mentales de la 


\section{Capítulo II- Naturaleza de la práctica}

partitura escrita (muchos pueden recordar "dónde están en la página" en determinado punto de la obra). Aunque hay quienes hablan de memoria "fotográfica", esta denominación debería ser relativizada. La investigación actual en lectura a primera vista ha proporcionado un cúmulo interesante de información sobre cómo funciona el campo visual de un instrumentista (Lehmann \& McArthur, 2002). La memoria visual puede además involucrar la visualización del instrumento y/o la posición del cuerpo y asociarse asimismo a la memoria auditiva, cuando se echa mano a la audición interiorizada de un trozo u obra musical.

La memoria muscular (también llamada motora o kinestésica) involucra los movimientos que participan de la ejecución. La performance musical profesional presenta altísimas demandas (en complejidad y en velocidad) en términos de destrezas motoras, las cuales son desarrolladas por medio de numerosas repeticiones (Altenmüller \& Grühn, 2002). El grado de saliencia de este tipo de memoria oscurece algunas veces otros tipos. Los principiantes que se valen de la repetición como estrategia de aprendizaje suelen memorizar por esta vía, mientras que los expertos desarrollan otros recursos que les permitan un mayor control sobre la tarea.

En una investigación con músicos novatos y músicos profesionales de orquesta, la mayoría manifestó que la memorización tenía lugar durante la práctica y sin esfuerzo consciente (Hallam, 1997). En consonancia con la investigación de Hallam, Chaffin et al. (2002) registraron idénticas expresiones en músicos profesionales. El avance 
Capítulo II- Naturaleza de la práctica

de la investigación neurocientífica de las últimas décadas ha proporcionado interesantes hallazgos que explican el funcionamiento del programa motor en la ejecución musical (Altenmüller \& Grühn, 2002; Altenmüller, 2006).

\subsection{Etapa de afianzamiento}

Cuando un ejecutante ha conseguido tocar la obra de memoria continúa sin embargo la práctica. La investigación sobre esta etapa es todavía escasa, ya que normalmente los estudios han llegado hasta el momento de la memorización. La investigación de Chaffin et. al (2002) ha proporcionado información acerca de la práctica más allá del punto mismo de la memorización: tras 17 sesiones la pieza fue memorizada, siguiendo luego otras 27 sesiones en que la pianista tocó sin partitura. Aun cuando esta instancia sea de crucial importancia en la consolidación de una obra, no se ha investigado aún el monto de tiempo que es necesario invertir en el repaso de la misma. Mishra (2004), tomando en cuenta las estrategias empleadas por el instrumentista, subdivide el repaso en tres instancias:

(i) Reaprendizaje: se reorganiza la información musical y se testea la eficacia de las pistas ejecutivas ensayadas en las instancias previas. El número se reduce a las más necesarias y muchas podrán ser reemplazadas y eliminadas. Existe la posibilidad de establecer una 
suerte de jerarquía en las pistas para la memorización (Williamon \& Valentine, 2002).

(ii) Automatización: involucra tanto la repetición extendida a los fines de automatizar movimientos físicos (i.e. sin control ni esfuerzo consciente) como la interacción de ellos con las pistas de recuperación ensayadas. En el estudio de Chaffin y sus colegas (2002) la pianista ensaya reiteradamente el Presto del Concierto Italiano de Bach y gran parte del reto consiste en la posibilidad de operar con destreza en la recuperación desde la memoria mientras tiene lugar un movimiento físico altamente activo y en la trampa de los "conectores", aquellos pasajes que pueden desembocar en distintas partes de la estructura de la pieza. Dado que la recuperación de la MLP conceptual es considerablemente más lenta que la memoria motora, uno de los desafíos principales de la automatización consiste en hacer coincidir la recuperación conceptual y la motora de la información alojada en la MLP con un costo atencional mínimo.

(iii) Mantenimiento: los ejecutantes expertos sostienen un vasto repertorio de obras que deben estar disponibles frente a demandas de mayor o menor urgencia que les presentan sus carreras profesionales. El objetivo es conservar la destreza en la recuperación de la información musical almacenada. Esta instancia no ha sido investigada de manera sistemática. En 12 entrevistas Michael Wessel (2012) recoge las impresiones de músicos prominentes (instrumentistas y cantantes) sobre sus carreras y la manera en que practican y conservan el repertorio. La heterogeneidad de este 
Capítulo II- Naturaleza de la práctica abanico de testimonios plantea un escenario desafiante para las futuras investigaciones sobre el campo. 
PARTE II

EVIDENCIA EMPÍRICA 


\section{Capítulo III}

\section{Objetivos y Metodología}

\section{Objetivos}

Esta investigación parte de un interés por las dificultades que ofrecen las obras contrapuntísticas en relación a la memorización y recuperación frente a eventuales fallas en la ejecución musical. Aun cuando pueda tener beneficios tanto para intérpretes como para el público, la ejecución memorizada constituye una tarea ardua e incluso un obstáculo, tanto para expertos como para principiantes. Una falla de memoria puede conllevar consecuencias altamente negativas en la autoestima del músico y poner en riesgo la continuidad de una interpretación. Cuando se trata de una fuga (u otra obra de factura semejante), la memorización suele ser un escollo incluso en músicos experimentados que no encuentran dificultades frente a otro tipo de discursos.

La investigación reciente (Chaffin \& Imreh, 1997) ha dilucidado el rol que juega la estructura jerárquica de la música en los procesos de codificación y recuperación del material alojado en la MLP. Sin embargo, una de las limitaciones de la Teoría generativa de la música 
tonal ha sido su "incapacidad para brindar descripciones estructurales separadas para diferentes líneas contrapuntísticas" (Lerdahl, 1988: 344). No se han realizado hasta el momento estudios sobre la memorización experta de obras construidas sobre principios imitativos y por ello el carácter exploratorio de esta tesis, cuyo objetivo central es el de identificar la naturaleza y carácter de las estrategias de práctica puestas en juego al encarar la memorización de una composición en estilo imitativo, en la cual el agrupamiento se ve obstaculizado por la configuración misma de la textura musical.

\section{Metodología}

\subsection{Sujeto}

La pianista realizó estudios de grado en piano en el Conservatorio Nacional "Carlos López Buchardo" de la Ciudad Autónoma de Buenos Aires. En la actualidad se desempeña como docente de instrumento y pianista acompañante, tanto en la esfera privada como en instituciones públicas del medio. Lleva adelante una intensa agenda de conciertos en calidad de solista y camarista, estando por ello familiarizada con el aprendizaje de nuevo repertorio. 


\subsection{Estímulo}

Se seleccionó para el experimento la Fuga Nro. 4 BWV 849 del primer volumen de Das Wohltemperierte Klavier de Johann Sebastian Bach. Las fugas del clave bien temperado son material de estudio obligado en los programas de formación de cualquier pianista y obras normalmente requeridas en concursos y/o exámenes. Consta de 115 compases y el tempo promedio de ejecución total es de 4:30 minutos. Debe señalarse que la pianista no había tocado ni enseñado la pieza con anterioridad a la experiencia.

La fuga consta de 5 voces y está construida sobre tres ideas temáticas. El tempo lento de la obra fue un aspecto al que se atendió con miras a indagar el rol de la representación conceptual antes que la automatización del aspecto motor que hubiera sido preponderante en una fuga en tempo rápido.

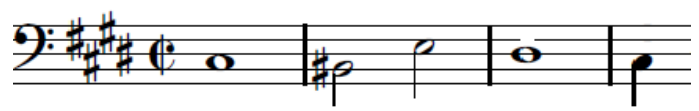

Ejemplo Nro. 1: C. 1-4

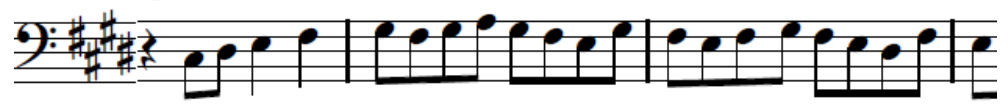

Ejemplo Nro. 2: C. 44-47 


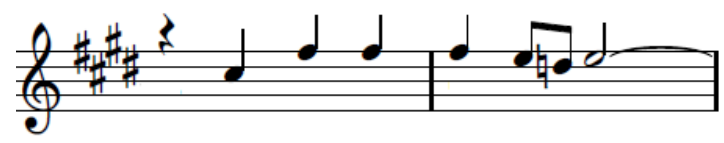

Ejemplo Nro. 3: C. 52-53

La densidad contrapuntística de la pieza es considerablemente alta si se tiene en cuenta el número de voces, alcanzado en muy pocos casos dentro de la producción bachiana. La integración de los estratos de esta fuga determina la aparición de secciones que se perciben como acórdicas, no solo como resultado de la consonancia armónica, sino también de la sincronía de ataques que opera como procedimiento igualmente integrador. En otras secciones, una mayor distintividad de las voces resulta de la elusión del componente sincrónico (una caracterización más detallada del concepto de textura puede encontrarse en Fessel, 2005). En relación a lo temático y no siendo objeto de este trabajo una discusión de tipo analítico, se adopta la categorización realizada por Keller (1965), según la cual el ejemplo seleccionado es un caso de triple fuga.

La pianista se valió para el estudio de la edición Ricordi, en una revisión realizada por Alessandro Longo. Esta edición proporciona digitaciones e indica también cada una de las entradas del sujeto de la fuga Está distribuida en cuatro páginas y esta característica de la edición impresa será un aspecto a considerar al momento de evaluar la segmentación del material durante la práctica. Aunque la pianista juzgó la obra moderadamente difícil, una de las dificultades tiene 
que ver con la distribución entre manos que se produce con las voces intermedias: una misma línea puede iniciarse en una mano e ir a otra.

\subsection{Procedimiento}

Esta tesis toma como punto de partida un estudio de caso y adopta como modelo el protocolo de investigación empleado por Roger Chaffin y Gabriela Imreh (1997) en la primera investigación sobre la memoria experta en la ejecución musical. Imreh grabó su práctica del Presto del Concierto italiano de Bach y también los comentarios que fue realizando durante los ensayos, en relación a los problemas y dificultades que se presentaban en la memorización de la pieza.

De la misma manera, la pianista de nuestra investigación grabó la totalidad de las sesiones de práctica desde el primer contacto con la obra, hasta que consideró que podía ejecutarla por completo de memoria. Es importante remarcar que, al igual que en la investigación de Chaffin \& Imreh (1997), se instruyó a la pianista sobre la importancia de que toda práctica fuera videograbada. Con ello se pretende poner a disposición del investigador la mayor cantidad de evidencia posible sobre el proceso de aprendizaje y memorización, al menos la que pueda recogerse de los períodos de ensayo de la instrumentista. 
Todas las grabaciones fueron hechas con una cámara de video Sony y un trípode, que fueron colocados de tal manera que la partitura, el teclado, el perfil y las manos de la pianista resultaran visibles y facilitaran así la observación del comportamiento y relación entre cada una de la partes (i.e. la relación visual con la partitura y/o con la posición de las manos y el teclado)

Se solicitó a la instrumentista que expresara verbalmente todo pensamiento vinculado a la práctica de la obra, a medida que esta tuvo lugar, ya sea en forma simultánea a la tarea o durante las pausas. La aplicación de esta metodología de "pensar en voz alta" goza de amplia aceptación en el campo de investigación, ya que la combinación de la observación con algún tipo de comentario verbalizado permite evidenciar aspectos que de otra manera permanecerían insondables. Por ejemplo, de la observación se desprende que un instrumentista atiende a la dinámica de un trozo, aun cuando no realice comentarios al respecto por considerarlo un aspecto no problemático. Teniendo en cuenta que la metodología puede interferir en la práctica y hacer que el sujeto no se encuentre lo suficientemente cómodo, se realizó una experiencia piloto con el preludio de la fuga y con el solo fin de familiarizar a la pianista con el procedimiento. 


\section{Capítulo iv}

\section{OBSERVACIÓN Y ANÁLISIS DE LA PRÁCTICA}

\section{Introducción}

Este capítulo presenta los resultados y análisis de la información relevada en el estudio de caso, en relación a las estrategias desplegadas por una pianista durante la memorización de una fuga de Bach. Partiendo de la observación de las grabaciones de video y el análisis de los comentarios y la práctica, se procuró obtener información sobre las actividades llevadas adelante durante el proceso de codificación y recuperación de una obra contrapuntística.

Se describe, en primer lugar, la distribución de los comentarios de la pianista a lo largo de las sesiones de práctica y se propone una categorización que atienda al contenido de los mismos. A continuación se detallan y analizan las fases o etapas en las cuales se ha dividido la práctica total de la fuga y, por último, se examinan aquellos componentes de la práctica que tuvieron una mayor pregnancia para el aprendizaje de la obra. 


\section{Distribución de los comentarios}

Los reportes verbales proporcionados por la pianista fueron fundamentales para el análisis de la tarea, ya que permitieron observar tanto la organización de la práctica en términos de planeamiento, como así también los puntos en que focalizó su atención.

La verbalización posibilita no solo una comparación abstracta entre lo hablado (semántico) y lo musical, sino también una elaboración física directa del movimiento y un soporte fundamental (Mantel, 2006). En ella es posible advertir las analogías y asociaciones que se establecen durante el proceso de codificación de una pieza y es, además, una ventana para conocer los estados de ánimo, intenciones y críticas del sujeto frente a su práctica. Hablar no solo sería la vía regia de la memorización, tal como se desprende de la metodología de Leimer \& Gieseking (1932) con sus tareas de descripción, previas a la práctica física. La didáctica del instrumento lo recomienda también porque permite clarificar ideas y explicitar la sucesión de acciones (Mantel, 2006).

Observaciones semejantes fueron planteadas décadas atrás por Donald Schön (1987): las descripciones que un sujeto realiza de su propia tarea son siempre construcciones, aunque dependan de los propósitos y sistemas lingüísticos de los que dispone. Constituyen intentos de volver explícitos y simbólicos aquellos conocimientos que son en principio tácitos y espontáneos, permitiendo con ello 
reestructurar estrategias para la resolución de problemas. Estos procesos de reflexión in situ (que no siempre son verbalizados) permiten realizar una evaluación de los objetivos alcanzados y determinar los pasos a seguir en lo sucesivo.

En nuestra investigación, los comentarios de la pianista fueron más frecuentes en las primeras sesiones de práctica, cuando la tarea tuvo un mayor número de interrupciones. En ellos es posible advertir:

(i) percepciones de la instrumentista sobre la tarea y la obra:

(...) tocar fugas me quema la cabeza. ${ }^{3}$

(ii) como componentes motivacionales:

Me gusta esta obra, creo que fue una buena elección más allá de los objetivos que pueda tener para la investigación. Es un desafío también, porque se trata de cinco voces... no es tan usual.

(iii) aspectos vinculados a la planificación del trabajo (al inicio de cada sesión enunció objetivos y actividades que llevaría a

3 Aclaración: Los comentarios de la pianista (sin importar la extensión) aparecen siempre en cursiva y en párrafo aparte, para evitar así la confusión con el resto de las fuentes que se citan. 


\section{Capítulo IV-Observación y análisis de la práctica}

cabo, y al finalizar una evaluación de lo realizado y de los pasos a seguir en la sesión siguiente):

Voy a tocar de memoria hasta donde llegué el día de ayer... veré que pasa y en base a eso cómo me organizaré hoy: si sigo avanzando o tengo que reforzar alguna parte en especial.

(iv) cuestiones básicas de la ejecución (selección y evaluación de la conveniencia de una determinada digitación)

(v)identificación de patrones de diverso tipo (ya sea sobre los materiales temáticos de la fuga, como también otros vinculados a la repetición de patrones de digitación en pasajes similares).

Tanto la frecuencia como los tipos de comentario registrados en nuestro estudio muestran una clara coincidencia con los hallazgos de investigaciones preliminares (Chaffin et al, 2002). La categorización propuesta debe ser entendida en un sentido flexible: así por ejemplo, un comentario acerca de la elección de una digitación puede involucrar cuestiones vinculadas a la estructura e incluso a la planificación de la práctica:

(...) esta digitación que estuve practicando ayer no es buena, no puedo aplicarla en este otro pasaje; voy a tener que encontrar una que me permita usarla también acá. 
Se ha considerado siempre el rasgo de mayor pregnancia al momento de analizar cada ejemplo, lo cual ha sido algunas veces difícil de estimar.

Los casos de superposición de comentarios y acción fueron escasos; es posible inferir que, frente a tareas complejas, la verbalización en simultáneo se vuelva un obstáculo y por ello cualquier acotación verbal sea diferida o simplemente omitida.

\section{Estructura de la práctica}

La práctica de la fuga, desde el primer contacto con la obra hasta su ejecución integral sin partitura demandó un total de 17 horas y 20 minutos, tiempo total que se distribuyó en 43 ensayos con un promedio de 24 minutos cada uno. La experiencia tuvo lugar entre los meses de diciembre y enero, en un período de receso en las actividades habituales de la pianista, circunstancia que posibilitó la continuidad de la tarea sin imprevistos que pudieran interrumpir su desarrollo. La distribución y número de ensayos, así como la duración de los mismos se dejaron a criterio de la instrumentista y no se registraron pausas significativas entre ellos que pudieran impactar en el desarrollo y planeamiento de la tarea. La frecuencia de las sesiones de práctica fue diaria, excepto en dos oportunidades en que dos ensayos tuvieron lugar durante la misma jornada. 
Es posible estructurar la práctica en tres grandes partes: una primera etapa destinada a la lectura de la partitura (sesiones 1 a 17), una segunda etapa en la que se inició la memorización consciente de la pieza (sesiones 18 a 41) y una tercera y última en que la pianista fue capaz de la ejecución memorizada de la fuga y consideró alcanzado el objetivo inicial (sesiones 42 y 43 ).

La Tabla Nro. 1 y el gráfico presentados a continuación permiten observar la distribución cuantitativa del tiempo total invertido en el aprendizaje de la obra. Es posible advertir que los ensayos sin partitura demandaron mayor cantidad de tiempo $(68,27 \%)$ y la etapa final estuvo dentro de los parámetros normales, es decir considerando que la única tarea consistió en evaluar si la memorización de la pieza se había alcanzado realmente $(3,37 \%)$. El tiempo total de la etapa inicial en la que se empleó la partitura, y cuando aún no se había emprendido la memorización consciente, podría considerarse elevado $(28,37 \%)$. Esto puede deberse a que no hubo práctica fuera del instrumento, de suerte que la planificación y organización de la tarea fue surgiendo a medida que la pianista se familiarizó con la pieza. 
Tabla Nro. 1

\begin{tabular}{|c|c|c|c|c|}
\hline $\begin{array}{c}\text { ETAPA DE LA } \\
\text { PRÁCTICA }\end{array}$ & $\begin{array}{c}\text { TIEMPO EN } \\
\text { MINUTOS }\end{array}$ & $\begin{array}{c}\text { NÚMERO DE } \\
\text { SESIONES DE } \\
\text { PRÁCTICA }\end{array}$ & $\begin{array}{c}\text { TIEMPO EN } \\
\text { HORAS }\end{array}$ & $\begin{array}{c}\text { \% SOBRE EL } \\
\text { TOTAL DE LA } \\
\text { PRÁCTICA }\end{array}$ \\
\hline Lectura & 295 & 17 & $4: 55$ & 28,37 \\
\hline $\begin{array}{c}\text { Memorización } \\
\text { consciente }\end{array}$ & 710 & 24 & $11: 10$ & 68,27 \\
\hline Evaluación & 35 & 2 & $0: 35$ & 3,37 \\
\hline Totales & 1040 & 43 & $17: 20$ & 100 \\
\hline
\end{tabular}

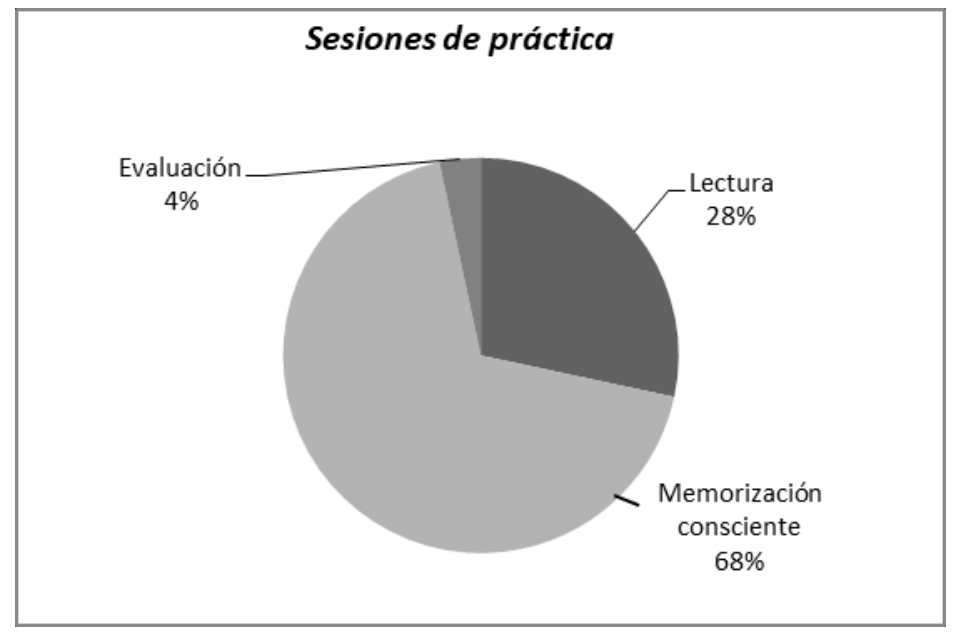




\subsection{Lectura}

Gran parte del trabajo de esta primera etapa estuvo destinado a la elección de digitaciones o a la realización de actividades tendientes a lograr algún tipo de automatismo. La pianista recurrió siempre al uso instrumento; no se observa el uso de la práctica mental previa a la práctica física, ni tampoco el empleo de grabaciones de audio o video de otros intérpretes como modelos que pudieran servir de soporte en algún sentido.

Al momento de adquirir una imagen global de la obra, la pericia de la instrumentista en destrezas vinculadas a la repentización jugó un rol clave, ya que antes que recurrir a modelos externos, pudo valerse de la propia lectura.

Aun cuando el objetivo de esta primera etapa no fue la memorización consciente de la pieza (sino la lectura de la fuga), la observación de la práctica y los comentarios de la pianista ofrecen evidencias contundentes acerca de la consolidación de automatismos que involucran distintos tipos de memoria: motora, en la elección y ensayo de digitaciones en puntos problemáticos; visual, en tanto se configuró un ordenamiento y segmentación de la obra atendiendo a la distribución en páginas de la edición empleada; auditiva, que se manifiesta en la corrección local de los errores y conceptual, en diverso grado a partir de un uso más o menos consciente de la estructura. 
El objetivo de la práctica en esta etapa consistió en descifrar los aspectos más elementales de la obra:

(...) lo único que estoy buscando es pegarle a las notas, cualquier otra cosa que haga es colateral.

Gran parte de las estrategias y actividades a considerar estuvieron presentes también en la segunda etapa. La principal diferencia radica en que, mientras la pianista ensaya con la partitura, el foco de atención principal está puesto en la decodificación del texto musical y la construcción de automatismos de tipo muscular. Es por ello que los componentes explícitos de la práctica fueron más bien endebles y aun cuando la frecuencia de los comentarios fue mayor, se observa una mayor imprecisión en el contenido de los mismos.

La segmentación (cortes y reinicios) obedeció esencialmente a la paginación de la fuga antes que a la estructura de la obra y lo mismo puede hacerse extensivo a la planificación del trabajo:

Mañana termino de leer la segunda página y repaso la primera.

\subsection{Memorización consciente}

La segunda etapa se inició cuando la pianista decidió encarar de manera consciente la tarea de memorización y, para ello, abandonó el uso de la partitura durante los ensayos. Abarca un total de 11 horas y 10 minutos distribuidas en 24 sesiones. Si bien la partitura fue una fuente de consulta permanente en esta etapa, la pianista no 


\section{Capítulo IV-Observación y análisis de la práctica}

recurrió a ella durante la ejecución sino mayormente en los intervalos o pausas. La atención estuvo puesta en la observación de las manos y el establecimiento y ensayo de las pistas performativas necesarias para la recuperación de la información en el momento de la ejecución memorizada.

Una estrategia que empleó al inicio de cada sesión fue el repaso ( $\sin$ partitura) de lo aprendido en el ensayo anterior. Esta revisión le permitió reflexionar, realizar ajustes y evaluar a cada paso su desempeño. En función de ello se mostró flexible, introduciendo modificaciones en lo planificado y replanteando objetivos toda vez que estimó que los resultados no respondían a lo esperado:

Creo que voy a tener que trabajar de nuevo en esta sección porque tengo muchas lagunas todavía, igualmente voy a avanzar un poco pero no tanto como tenía pensado.

La memorización consciente de la pieza demandó la aplicación de estrategias conscientes, que permitieran establecer las pistas performativas necesarias para una recuperación exitosa desde la MLP. En ese sentido, la pianista privilegió aquellos puntos o pasajes problemáticos que no habían sido automatizados en la práctica de la primera etapa, donde la memorización tuvo lugar en un sentido implícito.

Uno de los rasgos más sobresalientes en esta etapa es un incremento pronunciado en el número y la frecuencia de comentarios que se 
vinculan al reconocimiento y análisis de patrones melódicos (los temas de la fuga). La pianista comparó y describió verbalmente semejanzas y diferencias entre las distintas apariciones del material:

Acá es casi igual pero tengo que estar atenta porque el si es sostenido... iacá aparece el tema otra vez en el tono principal!

\subsection{Evaluación}

La última etapa tuvo lugar cuando la pianista consideró que estaba en condiciones de tocar la fuga de manera total y sin interrupciones. El tiempo total de esta última fase fue de 35 minutos distribuidos en dos sesiones: en el penúltimo video la ejecución fue relativamente estable (las fallas de memoria determinaron leves distorsiones en lo rítmico pero no pusieron en riesgo la continuidad del discurso) y durante la última sesión la pianista logró dos ejecuciones fluidas de la fuga.

La ejecución memorizada de toda la obra fue el punto de cierre del experimento y en ese sentido fue planteada la consigna original con la que se instruyó a la pianista en el momento de iniciar las grabaciones de la práctica. Si bien la instrumentista alcanzó una versión ajustada en la penúltima sesión, estimó que eran necesarias al menos dos ejecuciones más: 


\section{Capítulo IV-Observación y análisis de la práctica}

Está bastante bien, sin embargo quisiera volver a tocar la fuga al menos un par de veces más para asegurarme de que no fue casualidad. Ahora la voy a dejar descansar.

Es posible observar en esta decisión un enfoque estratégico de la tarea, en términos organización y distribución del tiempo. La práctica distribuida de la obra en esta instancia de evaluación (las últimas dos sesiones transcurrieron en días diferentes) permitió a la pianista estimar la estabilidad de las representaciones mentales construidas y asegurarse así de que había tenido lugar una retención en la MLP, antes que un almacenamiento temporal -y por ende efímero- en la MCP.

Esta tesis se ha ocupado de las estrategias empleadas en la práctica y memorización de una obra contrapuntística durante las etapas iniciales de la codificación y recuperación. Las estrategias y actividades necesarias para el mantenimiento y consolidación de las representaciones mentales construidas no han sido estudiadas en este trabajo y son, en todo caso, objeto de futuras investigaciones. Lo interesante de esta última etapa es observar un rasgo de pericia en términos metacognitivos, en tanto la pianista pudo establecer de manera exitosa el momento en que la evaluación tendría lugar y las estrategias para llevarla a cabo. 


\section{Componentes de la práctica}

\subsection{Identificación de patrones y uso de la estructura}

Durante la lectura de la fuga y los ensayos con partitura, no hubo comentarios vinculados al uso de la macroestructura. Tampoco la identificación de patrones melódicos fue un componente explícito de la práctica en esta primera etapa, lo que se infiere, al menos, de la escasez e imprecisión de los comentarios referidos a las ideas temáticas de la fuga. Esta situación se revierte al iniciarse los ensayos sin partitura, cuando la pianista recurrió a estrategias conscientes que le permitieran memorizar la pieza.

La observación y análisis de la práctica, en los cortes y reinicios, corroboran la presencia de un reconocimiento implícito -o por lo menos no verbalizado- de los patrones melódicos más salientes. Cabe señalar que en una fuga la segmentación en secciones es más bien dificultosa y no necesariamente inequívoca y la macroestructura está determinada por secciones de igual jerarquía delimitadas por procesos cadenciales ${ }^{4}$. Esta observación analítica permite explicar la

4 "Librémonos de creer en la existencia de reglas 'normales' para la estructura formal de la fuga; si así fuera, nos veríamos obligados a declarar 'anormales' todas las fugas de Bach. Cada fuga de la música culta tiene su propia forma emanante de sus fuerzas internas. 'Normas' existen en todo caso para la fuga 'escolástica', que es algo parecido a una abstracción simplificada para los estudiosos del contrapunto decimonónico. De esto deriva también la 
ausencia de comentarios referidos a los niveles macroestructurales, situación que es posible observar en todas las etapas de la práctica, tanto durante la codificación (i.e. la lectura de la obra) como en el ensayo de las pistas performativas que garanticen la recuperación posterior (i.e. cuando la obra empieza a ser ensayada sin partitura).

En la práctica se observa, sin embargo, un uso no declarado de las cadencias como puntos preferidos para la segmentación. Aun en aquellos lugares en los que el cambio de página se interpuso, la pianista privilegió en todo momento los procesos cadenciales. En el ejemplo Nro. 4 se muestra uno de los lugares en los cuales procedió según lo descripto: el primer tiempo del compás 35 (cadencia perfecta sobre Mi mayor) fue un punto preferido para cortar y el segundo tiempo -en la voz de la soprano- fue adoptado como comienzo de un nuevo fragmento.

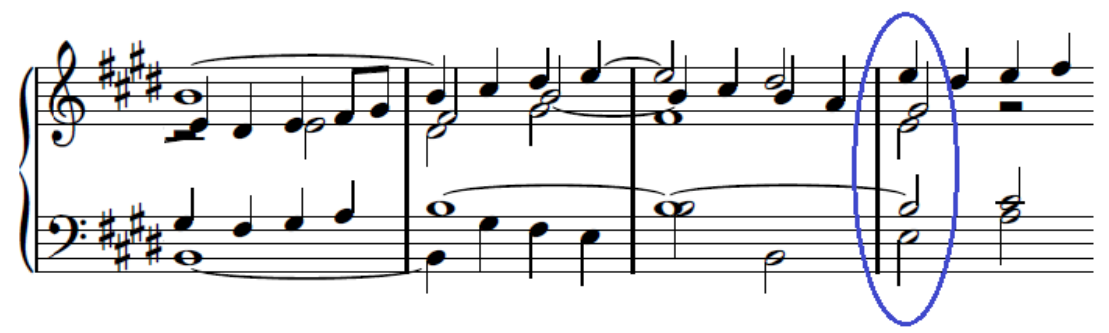

Ejemplo Nro. 4: C. 32-35

apreciación absolutamente falsa de que una fuga deba tener tres partes[...]" H. Erpf (1967 en Forner \& Wilbrandt, 1993: 273) 
El tratamiento textural de una fuga privilegia la idea de continuidad y por ello las cadencias aparecen encubiertas o veladas por el movimiento de uno o varios estratos, de suerte que la articulación armónica se vea más o menos debilitada por el tratamiento rítmico. En el Presto del Concierto Italiano de Bach -que Chaffin \& Imreh (1997) emplean para llevar adelante su investigación- la estructura de agrupamiento es unívoca (se trata de un rondó) y por ello opera de manera predominante al momento de organizar las tareas para la práctica y la memorización del trozo.

\subsection{Reconocimiento y corrección de errores}

La observación de la práctica y los comentarios proporcionados ofrecen evidencias para analizar el tratamiento del error, entendiendo por error la divergencia no deseada entre lo prescripto por el texto musical y lo que el músico ejecuta. Los errores constituyen aportes de enorme valor para el investigador, una suerte de "ventana" a la práctica del músico, que permiten una descripción, más o menos certera, de los procesos de comprensión que un instrumentista pone en juego durante el estudio de una pieza.

La Psicología de la Memoria aporta un dato clave al momento de estimar el grado de permanencia o retención de estas "fallas". En algunos casos, los errores aprendidos (es decir alojados en la MLP) pueden ser resultado de la repetición (e.g. una nota equivocada en un pasaje particular) y llegan a formar parte de un almacenamiento 
en cierto grado inflexible. Sin embargo, otras fallas que pueden producirse en la práctica (e.g. en la lectura a primera vista) no pueden ser caracterizadas en el mismo sentido: el almacenamiento temporario necesario para la realización de una tarea no determina per se una retención a largo plazo. Esta diferenciación es crucial para la práctica instrumental y la enseñanza, en tanto permite entender algunos errores como parte constitutiva y necesaria del proceso de aprendizaje de una obra, sin temor a que puedan ser almacenados en la memoria implícita.

En la primera fase de la práctica, cuando la pianista usó la partitura, es posible inferir que los errores obedecen a cuestiones vinculadas a la enculturación y la experiencia previa: algunos comportamientos del discurso tonal, y en algún grado también los programas motores correspondientes, determinan equivocaciones vinculadas a la activación de representaciones mentales de la notación musical y de expectativas melódicas y armónicas (Lehmann \& Kopiez, 2009). Existe consenso al momento de sostener que estas expectativas son altamente poderosas y pueden dar lugar a alternativas plausibles, producto del contexto mismo de la obra, como también de los conocimientos previos almacenados (Lehmann \& Ericsson, 1996).

Los comentarios de la pianista reflejaron el uso frecuente de estrategias analíticas durante la segunda etapa de la práctica, en la que uno de los objetivos centrales fue consolidar un marco conceptual apropiado para el desarrollo de la memoria explícita. El conocimiento explícito puesto en juego en esta instancia involucra el 


\section{Capítulo IV-Observación y análisis de la práctica}

establecimiento y ensayo de pistas performativas necesarias al momento de la ejecución memorizada, ya que permiten el monitoreo de la ejecución, así como la recuperación desde la MLP y la capacidad de sobreponerse a eventuales fallas sin poner en riesgo la continuidad de la interpretación. Tras reconocer patrones de diferente tipo, la pianista rastreó y comparó su aparición a lo largo de la pieza:

A ver si esto lo repite parecido en algún lado, ah sípero con si bemol [...]

[...] lo hace primero en el tono y después una quinta más arriba, estas cosas me van a ir ayudando a acordarme.

El ejemplo Nro. 5 permite analizar un ejemplo puntual de comportamiento que tuvo la pianista frente al error. Las desviaciones en la progresión melódica del bajo determinaron un punto en que la expectativa operó de manera dominante produciendo la activación y repetición de un patrón melódico y también muscular. Es interesante observar, además, que este error estuvo durante la lectura inicial y fue corregido a partir del uso de la partitura. Sin embargo, al iniciarse la segunda etapa de la práctica (i.e. memorización consciente), el error se repitió en el mismo punto. Esto permite afirmar que la desviación no había sido automatizada y el componente implícito se impone nuevamente operando en términos de expectativa (patrones ya aprendidos). En la práctica sin partitura 
la pianista advirtió y señaló de forma explícita esta desviación, de suerte tal que esta estrategia de tipo consciente le permitiera monitorear el pasaje:

Acá el dibujo cambia, tengo que estar atenta porque siempre sigo de largo en estos compases. Si llega a pasar eso... no sé después como voy a poder seguir adelante.

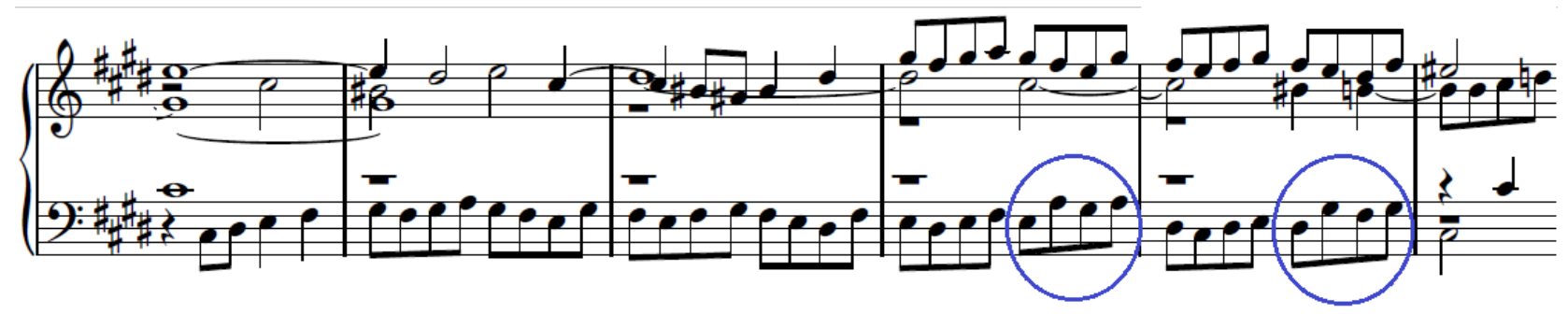

Ejemplo Nro. 5: C. 44-49

En otros casos la estimación del error se valió de la comparación como estrategia analítica, estableciendo relaciones de semejanza/diferencia entre las diferentes apariciones de un mismo patrón (i.e. los diferentes temas de la fuga). Aunque no sería exacto caracterizar este comportamiento como claramente macroestructural, es posible afirmar que se trata de un intento por extender el reconocimiento de patrones a un nivel más amplio, vinculado, por ejemplo, a la tonalidad de la fuga:

[...] claro, acá el tema está de nuevo en la tonalidad original, otra vez si sostenido [...] 


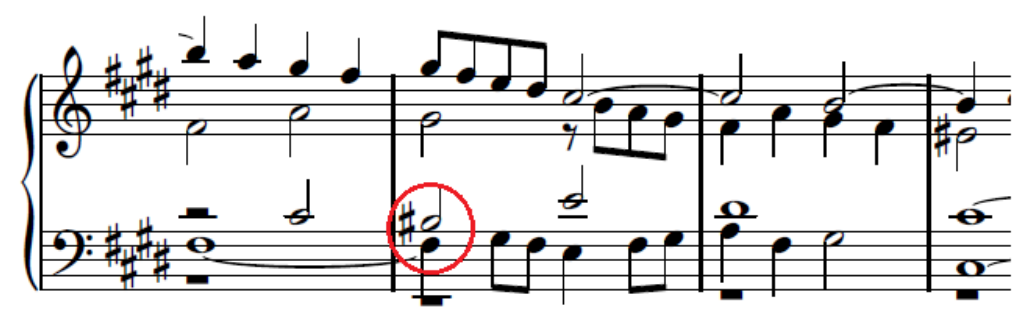

Ejemplo Nro. 6: C. 25-28

\subsection{Procesamiento de la información}

En relación al uso de estrategias de procesamiento, la pianista hizo un manejo flexible de las diferentes alternativas. El procesamiento de tipo holístico fue predominante desde el inicio mismo de la primera lectura:

Voy a empezar leyendo toda la fuga para tener una idea de qué se trata y después poder organizarme.

Esta mirada holística de la pieza abarcó en el inicio de la primera sesión la totalidad de la pieza, un enfoque preferido por la tradición pedagógica e interpretativa para tener una primera idea global de la obra (Neuhaus, 1958; Chaffin et al, 2003). Sin embargo, una vez iniciada la primera lectura de la pieza, la pianista interrumpió la tarea justo al comienzo del compás 60 . Este corte coincide con el cambio de página en la edición empleada y la instrumentista 
aprovechó para hacer ajustes en la ubicación de la cámara. Entonces comenta:

No estuvo mal, pude acertar notas e incluso algunas digitaciones. Igual me cuesta porque hace mil años que no toco Bach ni fugas... me quema la cabeza. Es una fuga linda pero tantas voces me marean. Voy a retomar desde el comienzo y voy a concentrarme en esa primera parte.

Es posible observar varios aspectos en este comentario y en la primera lectura: en primer lugar, la adopción de un enfoque holístico, caracterizado por mínimos retrocesos para la corrección de errores, La percepción del error no obstruyó nunca el procesamiento, determinando así el reinicio de la tarea (como hubiera ocurrido si la pianista se hubiera valido de un procesamiento de tipo seriado). En esta primera interrupción es posible recoger una evidencia de cómo el uso del procesamiento holístico se adaptó a las dificultades y demandas de la tarea, permitiendo que el concepto de totalidad fuera redefinido en función de ello.

En segundo lugar, el comentario anterior de la pianista revela un componente vinculado con la enculturación y experiencia previa con el estilo, el cual operaría de manera determinante al momento de acotar porciones de la obra en función de un procesamiento holístico. La verbalización proporciona una evidencia clara de que la pianista estimó que la dificultad era mayor a lo que esperaba y que 
las causas tenían que ver con la dificultad intrínseca de la pieza, pero también con no estar familiarizada con el estudio de fugas.

\subsection{Cortes y reinicios}

Los límites de frase o sección constituyen puntos claves para la comprensión del discurso musical, lo cual resulta problemático en una textura imitativa, en la que esos puntos no ocurren en simultáneo. La Teoría Generativa de la Música Tonal de Lerdahl \& Jackendoff (1983) propone un modelo de estructura de agrupamiento, el cual, sin embargo, no es aplicable cuando se trata de diferentes líneas contrapuntísticas. Como lo afirman los propios autores, esta teoría es válida solamente para la música homofónica, en la cual una única estructura de agrupamiento se aplica a toda la textura (tal el caso del Presto del Concierto Italiano de Bach que Chaffin emplea en su estudio con la pianista Gabriela Imreh). En las fugas y otros géneros contrapuntísticos que se valen de la imitación como principio compositivo, los diferentes estratos demandan límites de agrupamientos diferentes, que no son exactamente verticales (Temperley, 2001).

En idéntico sentido es posible analizar la lectura a primera vista de obras en estilo imitativo. Ya en 1943 Weaver (en Lehmann \& Kopiez 2009) analizó el movimiento ocular durante la lectura y determinó que, en discursos polifónicos, esta transcurría en patrones de zigzag horizontal que seguían el curso de las líneas en las diferentes voces. 
En obras homofónicas, en cambio, el zigzag se produce de arriba hacia abajo.

En nuestra investigación fue posible observar al menos dos comportamientos en relación al agrupamiento: (i) las cadencias más evidentes (i.e. aquellas en la que confluyen un mayor número de líneas) prevalecieron siempre por sobre cualquier otro criterio y (ii) los comienzos preferidos fueron los más salientes, ya fuera por el registro (i.e. líneas o voces extremas) o por un mayor movimiento en términos de figuración rítmica (e.g. el segundo tema en corcheas, c. 44).

La notación a dos pentagramas empleada tradicionalmente en la escritura pianística obedece a una cuestión física (i.e. la distribución de manos), pero a costa de oscurecer la configuración de la textura. En la fuga de Bach empleada en nuestro estudio, esta situación es inclusive más pronunciada, si se tiene en cuenta que se trata de 5 voces, número que desborda las posibilidades mismas de la grafía ${ }^{5}$.

\footnotetext{
${ }^{5}$ El uso convencional de plicas diferentes para hacer visible la diferenciación entre voces se ve sobrepasado y puede determinar una misma tipología en voces contiguas (las dos escritas con la plica hacia arriba o hacia abajo)
} 


\subsection{Análisis}

Si bien existen elementos analíticos que, con mayor o menor grado de explicitud, se pusieron de manifiesto en los demás componentes de la práctica, nos ocupamos aquí de aquellas consideraciones analíticas particulares de la fuga. Al observar los ensayos y examinar los comentarios de la pianista es posible rastrear los paradigmas de análisis, algunos criterios interpretativos que podrían desprenderse de su aplicación (sin pretender establecer una relación de causalidad entre ambos aspectos) y su contextualización histórica dentro de la tradición interpretativa.

El uso de una terminología específica del análisis (de cuya pertinencia no se ocupa esta tesis) fue más bien esporádico y no sistemático. Se registraron comentarios referidos a la distinción entre episodios y las entradas del tema, lo que deja traslucir algún tipo de manejo del análisis escolástico de la fuga:

Acá empieza un episodio... o sea, el tema no está.

Tengo que tener bien claro dónde aparece el motivo para hacerlo oír. Son cinco voces, a veces se me pasan por alto las entradas.

A medida que la práctica avanzó, la atención se dirigió hacia el reconocimiento de patrones melódicos en las diferentes apariciones y la necesidad de que su interpretación lograra ponerlos de relieve. Con ello se evidencia la adhesión a un paradigma decimonónico que señala la necesidad de poner en primer plano el sujeto de la fuga en 
cada una de sus apariciones o entradas (Tureck, 1960). Esta concepción de raigambre romántica, la cual cuenta aún con extendida aceptación en la pedagogía actual, ha sido objeto de críticas por parte de autores que han examinado las vinculaciones entre análisis e interpretación (Rothsthein, 1995).

El desafío que plantea la interpretación de una fuga es advertida por la pianista, aunque no pueda explicar las razones de esa complejidad:

[...] con las fugas es todo siempre más complicado que con otras obras, y también con la memorización: siempre se necesita un esfuerzo extra... no sé por qué [...]

\subsection{Práctica mental}

El uso de la práctica mental estuvo circunscripto a dos situaciones: la primera vinculada a la evaluación y planificación de la tarea:

"ayer había dicho que iba a seguir avanzando pero después estuve pensando que mejor me conviene concentrarme en esta página el día de hoy".

No se registraron, sin embargo, actividades sobre la obra que prescindieran de la práctica física al instrumento (e.g. trabajo sobre la partitura, verbalización y/o aplicación de técnicas de visualización y concentración enfocada). 
Un segundo uso observado en los videos consistió en la aplicación de la práctica mental en el interior de las sesiones, es decir, en las pausas y momentos en que la práctica física se suspendió y la pianista observó la partitura en silencio. Resulta difícil ponderar con cierto grado de certeza el uso de la PM en esos intersticios, aunque los comentarios que siguieron ofrecieron evidencias de algún tipo de reflexión sobre el material. El análisis de patrones (generalmente de tipo comparativo) fue un aspecto predominante y no hubo referencias, en cambio, a cuestiones vinculadas a la práctica física (e.g. digitaciones)

\subsection{Estilos sensoriales}

La Tabla Nro. 2 nos permite cotejar la presencia de estilos sensoriales de memorización en las dos primeras fases de la práctica. El predominio de los estilos visual y auditivo fue ostensible de diferente manera en cada una de las fases de la práctica.

Durante la práctica con partitura, la observación estuvo dirigida de manera casi exclusiva al texto musical y la pianista no atendió a la posición ni al movimiento de las manos. Este comportamiento propioceptivo proporciona una clara evidencia de la pericia de la instrumentista en la repentización o lectura a primera vista, práctica con la que se encuentra familiarizada por su experiencia como pianista acompañante. 
Al iniciarse la segunda etapa, destinada a la memorización consciente de la obra, el estilo visual se mostró aún más prominente, pero el foco de atención se desplazó entonces a las manos. La observación de los videos proporciona una evidencia clara de cómo la pianista monitoreó las tareas de recuperación apelando a lo visual, una pista que paradójicamente, no había sido ensayada durante la lectura de la fuga.

El empleo de un estilo sensorial de tipo auditivo no fue observable en un sentido explícito, pero puede inferirse su uso para advertir errores. En la primera parte esto estuvo subordinado siempre al uso de la partitura, que actuó como soporte central. En la segunda fase, cuando la pianista prescindió de la notación, lo auditivo se constituyó en la herramienta central al momento de corregir o revisar aquellos puntos más controvertidos de la obra. 


\begin{tabular}{|c|c|c|}
\hline \multicolumn{3}{|c|}{ ESTILOS SENSORIALES DE APRENDIZAJE } \\
\hline & Lectura & $\begin{array}{c}\text { Memorización } \\
\text { consciente }\end{array}$ \\
\hline Visual & $\begin{array}{l}\text { - Uso de la } \\
\text { partitura: } \\
\text { permanente } \\
\text { - Monitoreo de } \\
\text { manos/teclado: no } \\
\text { se observó }\end{array}$ & $\begin{array}{l}\text { - Uso de la } \\
\text { partitura: solo en } \\
\text { pausas } \\
\text { - Monitoreo de } \\
\text { manos/teclado: } \\
\text { permanente } \\
\text { Memoria visual de } \\
\text { la partitura: no se } \\
\text { observó en un } \\
\text { sentido explícito. }\end{array}$ \\
\hline Auditivo & $\begin{array}{l}\text { - Uso opaco: No } \\
\text { hubo comentarios } \\
\text { pero puede } \\
\text { inferirse su uso en } \\
\text { un sentido } \\
\text { implícito (que solo } \\
\text { se confirma en la } \\
\text { etapa de } \\
\text { memorización) }\end{array}$ & $\begin{array}{l}\text { - Herramienta } \\
\text { preferida para } \\
\text { estimar y corregir } \\
\text { errores (evidencia } \\
\text { de aprendizaje } \\
\text { implícito en la } \\
\text { etapa previa) }\end{array}$ \\
\hline Muscular & $\begin{array}{l}\text { Repetición: no se } \\
\text { emplea con la } \\
\text { finalidad de } \\
\text { construir } \\
\text { automatismos de } \\
\text { tipo motor }\end{array}$ & $\begin{array}{l}\text { Repetición: no fue } \\
\text { posible observar } \\
\text { un componente } \\
\text { implícito } \\
\text { (automatismo) } \\
\text { que guiara la } \\
\text { recuperación. }\end{array}$ \\
\hline
\end{tabular}

Tabla Nro. 2: Estilos sensoriales de aprendizaje 


\section{Capítulo V}

\section{Conclusiones}

\section{Introducción}

Se ha presentado en esta tesis el análisis de un estudio de caso sobre las estrategias de práctica puestas en juego por una pianista profesional durante el aprendizaje y memorización de una fuga de Bach. El marco teórico, organizado en dos capítulos referidos a la memoria y la práctica en la ejecución musical, se propuso integrar los hallazgos de la investigación reciente en el campo con la tradición pedagógica e interpretativa. Este último capítulo presenta en primer lugar una síntesis y discusión de la evidencia empírica recolectada, a partir de los lineamientos teóricos postulados en la primera parte y esboza, en último término, conclusiones y aportes potenciales que sirvan de interrogante para futuras investigaciones en el tema. 


\section{Síntesis y discusión de la evidencia empírica}

Los fundamentos teóricos de este trabajo hunden sus raíces en dos áreas clave en las investigaciones sobre ejecución instrumental: la memorización y la práctica.

El primer capítulo describió los fundamentos teóricos de la Psicología en relación a la memoria humana y las estructuras y procesos que permiten explicar su funcionamiento. Estas teorías han priorizado un análisis estructural sin desmedro de las propiedades procesuales implicadas, tales como la codificación, el monitoreo y la recuperación de información. Estos paradigmas han guiado gran parte de los estudios sobre memoria experta aplicados a la ejecución instrumental.

Memorizar es una destreza compleja, que resulta de una interacción dinámica entre la experiencia y el contexto del sujeto. Por otra parte, la capacidad que tiene la memoria de operar depende, paradójicamente, del olvido. Es decir: es el grado de activación consciente de la información lo que permite determinar la existencia de componentes explícitos e implícitos que hacen posible que la memoria funcione. La ejecución musical no es la excepción y plantea, además, un terreno con nuevos desafíos, ya que a diferencia de otras memorias expertas involucra memoria motora. 
La construcción y consolidación de una memoria motora es el resultado de la práctica extendida que realiza un músico al momento de aprender una obra musical. El segundo capítulo presentó algunos marcos teóricos que puedan servir a una caracterización más definida del problema. Cuando un músico toca de memoria, recupera información desde la memoria a largo plazo, recurriendo al uso de pistas ensayadas que le permiten operar con un componente implícito (automatismo) y otro explícito (memoria conceptual).

En este punto es importante introducir una aclaración: cuando un instrumentista ensaya con partitura, esta le recuerda algo que ya sabe. Es decir: la notación opera como un andamiaje en la recuperación de información, pero el músico ya está “tocando de memoria". Se trata de una zona indefinida del proceso en la cual no puede prescindir aún de la partitura, pero tampoco hace una lectura de la misma en un sentido estricto. El punto en que se abandona el uso de la notación marca la internalización de pistas de recuperación que aseguren la activación de la información en el momento de tocar. Nuestra investigación fue diseñada teniendo en cuenta esto, ya sea para delimitar el comienzo y el final del estudio (que terminaría cuando la pianista pudiera tocar sin partitura la obra), como para organizar también la observación y el análisis de los resultados (i.e. etapas de lectura y memorización consciente). 


\section{Capítulo V-Conclusiones}

\subsection{La relación estructura - textura}

Las investigaciones previas sobre memoria experta se ocupan de establecer diferencias claras en relación al uso de la estructura musical que, profesionales y principiantes, hacen durante el aprendizaje de una obra. Sin embargo, las características formales de la obra elegida son muy diferentes a las de la fuga empleada en esta tesis. La experiencia de Roger Chaffin y la pianista Gabriela Imreh (1997) toma como estímulo para su investigación el Presto del Concierto Italiano de Bach. En esta obra la estructura jerárquica proporciona un esquema inequívoco, no solo para la codificación, sino también para la organización de la práctica. La memorización de una obra contrapuntística en estilo imitativo no puede ser explicada de la misma manera.

En nuestro estudio de caso hemos observado que operar en un nivel macroestructural (i.e. que excediera la identificación de patrones, tales como los representados por los temas de la fuga) se tornó dificultoso. Esta imposibilidad obedece a la naturaleza jerárquica del agrupamiento como proceso (Snyder, 2000), la cual colisiona con la configuración textural de la fuga, en la que los agrupamientos tienen lugar en las diferentes líneas de manera asíncrona. Esta asincronía determina al menos dos dificultades al momento de memorizar una obra contrapuntística en estilo imitativo. 
La primera dificultad se vincula al poder establecer con claridad una pista de recuperación en medio de la recurrencia de patrones melódicos en las diferentes líneas de la textura. Bregman (1990) ya señaló que si bien podemos percibir la presencia en simultáneo de múltiples líneas o estratos, no podemos atender más que a una; se trataría de una de las limitaciones de la atención humana, antes que al funcionamiento de la memoria tal como se describió en el primer capítulo de este trabajo. Cuando estamos frente a varias líneas, el ordenamiento temporal puede ser percibido con exactitud en una sola línea, aunque podamos movernos con rapidez entre las diferentes capas o estratos (Snyder, 2000). Con esto se explica que frente a una falla de memoria, muchas veces un instrumentista no pueda recuperarse y seguir adelante con la obra. Aun cuando la identificación y empleo de patrones melódicos mostró ser un componente relevante en nuestro estudio de caso, no hay evidencia suficiente de que con ello esté garantizado un monitoreo eficaz de la ejecución.

La segunda dificultad radica en la imposibilidad de delimitar articulaciones formales más claras, situación que se verifica de manera inexorable en una fuga. A pesar de los esfuerzos que se han hecho por construir un prototipo formal, lo cierto es que su aplicación al análisis ha resultado siempre forzada. Una revisión, incluso superficial, del repertorio muestra la singularidad de la fuga en términos de su sucesión de entradas, su plan armónico, la densidad de su textura y su estructura general (Kuhn, 1998). 
Con esto queremos señalar que el monitoreo global de la obra que realiza la pianista en el estudio de Chaffin no sería aplicable de igual manera a una fuga. La factura de las obras es, en cada caso, muy diversa y determina nuevas dificultades en términos de codificación y recuperación. En el esquema formal de un rondó (e.g. el Presto del Concierto (taliano) la recurrencia de un estribillo se comporta de manera totalmente diferente a las sucesivas presentaciones de un tema o sujeto en la fuga. Como se señala en el capítulo 2 de esta tesis (al referirnos a la trampa de los conectores), la repetición de un patrón y sus desviaciones representa un riesgo al momento de tocar de memoria y el instrumentista puede perder el control de la estructura global de la obra, aun cuando pueda seguir tocando. No sería exagerado afirmar que este es un costo que todo intérprete ha pagado alguna vez. Esta posibilidad no existe en una obra contrapuntística en estilo imitativo: la recurrencia de material melódico se produce en contextos siempre distintos (la relación entre corrientes o líneas es nueva para cada reaparición del tema) y por ello es habitual que cueste sobreponerse a la más mínima falla de memoria.

Es posible concluir entonces que gran parte de las dificultades que surgen al momento de aprender y tocar de memoria este tipo de obras sean el resultado de la construcción misma de las piezas. La configuración textural dificulta el agrupamiento, es decir: el uso de una de las funciones más elementales de la comprensión en música (Lerdahl \& Jackendoff, 1983). 


\section{Capítulo V-Conclusiones}

\subsection{Lo explícito y lo implícito en la práctica instrumental}

Uno de los temas centrales en el campo de la interpretación musical es el rol que juegan los componentes explícitos e implícitos al momento de tocar un instrumento. La práctica de un instrumentista puede incluir un sinnúmero de enfoques y estrategias (Barry \& Hallam, 2002), cuyo grado de eficiencia aumenta cuando son capaces de explicitar las debilidades y fortalezas de su rutina de trabajo, y logran planificar su tarea atendiendo a objetivos específicos, lo que la Psicología conoce como metacognición, es decir la reflexión sobre el propio pensamiento (Parncutt, 2007).

La práctica involucra por definición la repetición, la cual permite construir automatismos imprescindibles para la ejecución de cualquier destreza. La repetición plantea, sin embargo, paradojas: es la principal herramienta de un músico durante su práctica y también su principal enemiga. No solo por cuestiones físico-motoras y cognitivas (a las cuales ya nos hemos referido en el capítulo 2 de este trabajo), sino porque puede además coartar la frescura y espontaneidad que se espera de una interpretación, y reducirla a la mera reproducción.

En este punto nuestra tesis establece también una diferencia con la investigación preliminar de Chaffin \& Imreh (1997). En ella la velocidad de la pieza permitió observar el comportamiento de ambos tipos de memoria (explícita e implícita) durante el aprendizaje de 
una obra, contrastando la activación de lo automatizado (i.e. memoria implícita) en superposición a lo explícito. Uno de los objetivos de la práctica de Imreh fue lograr que la recuperación de ambos tipos de memoria coincidiera (aun cuando la memoria implícita es por definición más rápida que la memoria explícita o conceptual).

En nuestra investigación el componente de automatismo fue aminorado por la selección de la pieza. Se eligió una fuga en tempo lento para evitar así que la pianista recurriera a la repetición con miras a la automatización de patrones motores y se pusiera en juego lo antes posible el uso de estrategias explícitas. De esta manera, la memorización no fue algo que "simplemente ocurrió", afirmación repetida por muchos pianistas (Chaffin et al., 2002; Wessel, 2012), sino que requirió de una intervención consciente y deliberada por parte de la instrumentista.

En ese sentido, un primer análisis de los resultados de nuestro estudio de caso permite señalar dificultades por parte de la pianista al momento de comentar con mayor o menor grado de precisión el contenido de las tareas desplegadas. Esto no quiere decir de ningún modo que estemos frente de un conocimiento de tipo implícito. La selección de estrategias y la planificación de la práctica dan cuenta de un comportamiento experto por parte de la instrumentista, aun cuando la verbalización de ello haya sido por momentos exigua. 


\section{Aportes potenciales}

Quisiéramos insistir una vez más en el carácter exploratorio de nuestra investigación, la cual aborda una zona indeterminada de la práctica instrumental: la memorización frente a texturas contrapuntísticas en estilo imitativo. Es esa indeterminación la que nos ha llevado a intentar una descripción que permita definir con cierta claridad el problema, antes que conjeturar soluciones de manera superficial o apresurada (Schön, 1987).

En este sentido sería viable plantear algunos interrogantes para futuras investigaciones sobre el tema. En lo referido al uso de la estructura durante la codificación y el ensayo, un aspecto digno de atención sería determinar con mayor exactitud cómo opera la segmentación frente a la superposición entre líneas o corrientes melódicas.

En relación con esto, esta tesis describió algunos comportamientos preferidos por la pianista, cuyas implicancias debieran ser indagadas en próximas indagaciones. Sería posible avanzar en los estudios exploratorios sobre el tema a partir de la observación y análisis de actividades de lectura a primera vista, en las cuales sea posible indagar el rol de la expectativa (anticipaciones y errores) y las estrategias de procesamiento del material (lectura en zigzag). Los aportes del análisis estructural propuesto por Temperley (2001) y la caracterización del concepto de textura propuesta por Fessel (2005) 
constituyen un marco teórico insoslayable para cualquier investigación futura sobre el tema.

Otro aspecto que futuras indagaciones podrían plantear se refiere al uso de estrategias de práctica que atiendan a la factura de obras contrapuntísticas, las cuales podrían estar orientadas, por ejemplo, a la manipulación del texto musical original. Como ya hemos señalado en este trabajo, la escritura musical no facilita siempre la comprensión del discurso: en el caso de la notación pianística, la distribución habitual en dos pentagramas es una representación gráfica de la realización física (mano derecha e izquierda) antes que del discurso musical. En una fuga o textura a varias voces, este problema se vuelve más acusado. Sería entonces plausible registrar el impacto de estrategias vinculadas a subsanar esta carencia de la notación.

Esta tesis se propuso explorar las estrategias empleadas por una pianista experta para la memorización de una fuga de Bach. Al tratarse de un estudio de caso, somos conscientes de que su validez externa es relativa y, por ello, el propósito no es llevar a cabo ningún tipo de generalización que pueda determinar su aplicación inmediata a otros escenarios. La pianista que intervino en esta investigación no puede ser considerada una "muestra" representativa, en el sentido estadístico del término, y por ello los resultados no serían igualmente aplicables a una población más extensa. Pese a ello, confiamos en que los resultados de este estudio exploratorio 


\section{Capítulo V-Conclusiones}

puedan ofrecer herramientas para la reflexión sobre algunos de los temas que interesan a instrumentistas y pedagogos en su práctica cotidiana. 
114 
REFERENCIAS

Altenmüller, E. (2006). Hirnphysiologische Grundlagen des Übens. En U. Mahlert (Ed.) Handbuch Üben. Grundlagen, Konzepte, Methoden. (47-65). Wiesbaden: Breitkopf \& Härtel.

Altenmüller, E. \& Grühn, W. (2002). Brain Mechanisms. En R. Parncutt \& G. McPherson (Eds.) The Science and Psychology of Music Performance (63-81). Oxford: Oxford University Press.

Atkinson, R. C. \& Shiffrin, R. M. (1968). Human Memory: A Proposed System and Its Control Processes. En K. W. Spence \& J. T. Spence (Eds.). The Psychology of learning and motivation. Vol. II. (89122). Nueva York: Academic Press.

Barry, N. \& Hallam, S. (2002). Practice. En R. Parncutt \& G. McPherson (Eds.), The Science and Psychology of Music Performance (151-166). Oxford: Oxford University Press.

Berg, S. (2010) Üben: Vielfältige Lernwege im Spannungsfeld der unterschiedlichen Methoden und wissenschaftlichen Disziplinen. Tesis no publicada. Dr. Hoch's Konservatorium: Frankfurt am Main. 
Berry, W. (1989). Musical Structure and Performance. New Haven: Yale University Press.

Bitzan, W. (2010). Auswendig lernen und spielen. Über das Memorieren in der Musik. Frankfurt: Peter Lang.

Brown, S. \& Craik, F. (2000). Encoding and Retrieval of Information. En E. Tulving \& F. Craik (Eds). The Oxford Handbook of Memory. Nueva York: Oxford University Press, 93-108.

Burzik, A. (2006). Üben im Flow. En U. Mahlert (Ed.) Handbuch Üben. Grundlagen, Konzepte, Methoden.. Wiesbaden: Breitkopf \& Härtel, 265-286.

Chaffin, R. \& Imreh, G. (1997). "Pulling teeth and torture": Musical memory and problem solving. Thinking and Reasoning: Special Issue on Expert Thinking, 3, 315-336.

Chaffin, R. \& Logan, T. (2006). Practicing perfection: How concert soloist prepare for performance. 2 (2-3), 113-130.

Chaffin, R., Imreh, G., Lemieux, A. \& Chen, C. (2003). "Seeing the big picture": Piano practice as expert problem solving. Music Perception, 20, 461-485. 
Chaffin, R., Imreh, G. \& Crawford, M. (2002). Practicing perfection: Memory and piano performance. Mahwah, Nueva Jersey: Erlbaum Associates.

Chase, W. G., \& Ericsson, K. A. (1981). Skilled memory. En J. R. Anderson (Ed.). Cognitive skills and their acquisition. Hillsdale, Nueva Jersey: Lawrence Erlbaum Associates, 141-180.

Connoly, C. \& Williamon, A. (2004). Mental skill training. En A. Williamon (Ed.) Musical Excellence. Strategies and techniques to enhance performance. Oxford: Oxford University Press, 221-245.

Csikszentmihalyi, M. (1990). Flow: The Psychology of Optimal Experience. Londres: Harper Perennial.

Davidson-Kelly, K., Moran, N. \& Overy, K. (2012). Learning and memorisation amongst advanced piano students: a questionnaire survey. En E. Cambouropoulos, C. Tsougras, P. Mavromatis, K. Pastiadis (Eds) Proceedings of the 12th International Conference on Music Perception and Cognition and the 8th Triennal Conference of the European Society for the Cognitive Sciences of Music, Tesalónica Grecia.

De Vega, M. (1990). Introducción a la Psicología cognitiva. Madrid: Alianza Editorial. 
Ericsson, K. A. (1985). Memory Skill. Canadian Journal of Psychology. 39 (2), 188-231.

Ericsson, K. A. (1997). Deliberate practice and the acquisition of expert performance: An overview. En H. Jørgensen \& A. Lehmann (Eds.) Does practice make perfect? Current theory and research on instrumental musical practice. Oslo: Norges Musikhøgskole, 951.

Ericsson, K. \& Lehmann, A. (2011). Expertise. En M. Runco \& S. Pritzker (Eds.) Enciclopedy of Creativity. 2da Edición. Vol. 1, 488496.

Fessel, P. (2005). Heterogeneidad y concreción en la simultaneidad musical. Una caracterización teórica e histórica del concepto de textura. Tesis doctoral no publicada. Universidad Nacional de La Plata.

Gaunt, H. (2008). One-to-one tuition in a conservatoire: the perceptions of instrumental and vocal teachers. Psychology of Music 36(2): 215-245.

Gaunt, H. (2010). One-to-one tuition in a conservatoire: the perceptions of instrumental and vocal students. Psychology of Music 38(2): 178-208. 
Gellrich, M. (1987). Die Relevanz psychomotorischer Forschung für die Instrumentaldidatik. En G. Kleinen (Ed.) AuBerschulische Musikerziehung. Laaber: Laaber Verlag, 49-63.

Ginsborg, J. (2004). Strategies for memorizing music. En A. Williamon (Ed.) Musical Excellence. Strategies and Techniques to Enhance Performance. Nueva York: Oxford University Press, 123-141.

Ginsborg, G., Chaffin, R. \& Demos, A. (2014). Different roles for prepared and spontaneous thoughts: A practice-based study of musical performance from memory. Journal of Interdisciplinary Music Studies. 6 (2), 201-232.

Haddon, E. (2007). What does imagery mean to university music students and their professors? International symposium on Performance Science. 301-306.

Hallam, S. (1995). Professional musicians' approaches to the learning and interpretation of music. Psychology of Music, 23 (2), 111 128.

Hallam, S. (1997a). Approaches to instrumental music practice of experts and novices: Implications for education. En H. Jørgensen \& A. Lehmann (Eds.) Does practice make perfect? Current theory and research on instrumental musical practice. Oslo: Norges Musikhøgskole, 89-107. 
Hallam, S. (1997b). The development of memorization strategies in musicians: implications for education. British Journal of Music Education, 14, 87-97.

Hallam, S. (1997c). What do we know about practicing? Toward a model synthesising the research literature. En H. Jørgensen \& A. Lehmann (Eds.) Does practice make perfect? Current theory and research on instrumental musical practice. Oslo: Norges Musikhøgskole, 179-231.

Hallam, S. (2001) The Development of Expertise in Young Musicians: Strategy Use, Knowledge Acquisition and Individual Diversity', Music Education Research, 3: 1, 7-23.

Jørgensen, H. (2004). Strategies for individual practice. En A. Williamon (Ed.) Musical Excellence. Strategies and Techniques to Enhance Performance. Nueva York: Oxford University Press, 85104.

Jørgensen, H. \& Lehmann, A. (Eds) (1997). Does Practice Make Perfect? Current Theory and Research on Instrumental Music Practice. Oslo: Norges Musikhøgskole.

Keller, H. (1965). Das Wohltemperierte Klavier von Johann Sebastian Bach. Kassel: Bärenreiter. 
Lehmann, A. (1997). Acquired mental representations in music performance: Anecdotal and preliminary empirical evidence. En H. Jørgensen \& A. Lehmann (Eds.) Does practice make perfect? Current theory and research on instrumental musical practice. Oslo: Norges Musikhøgskole, 141-163.

Lehmann, A. \& Ericsson, A. (1998). Preparation of a Public Piano Performance: The Relation between Practice and Performance. Musicae Scientiae. Vol. II, Nro. 1, 67-94.

Lehmann, A. \& McArthur, V. (2002). Sight - Reading. En R. Parncutt \& G. McPherson (Eds.) The Science and Psychology of Music Performance. Oxford: Oxford University Press, 135-150.

Lehmann, A. \& Kopiez, R. (2009). Sight-reading. En S. Hallam, I. Cross \& M. Taut (Eds.) The Oxford Handbook of Music Psychology. Oxford: Oxford University Press, 344-351.

Leimer, K. \& Gieseking, W. (1931). Modernes Klavierspiel: Mit Ergäbzung Rhytmik, Dinamik, Pedal. Mainz: Schott.

Lerdahl, F. (1988), Tonal Pitch Space. Music Perception 5(3), 315-349.

Lerdahl, F. \& Jackendoff, R. (1983). A Generative Theory of Tonal Music, Cambridge: MIT Press. 
Lisboa, T., Chaffin, R. \& Logan, T. (2011). A self-study of practice: Words versus action in music problem solving. International Symposium on Performance Science, 517-522.

Mahlert, U. (2006). Was ist Üben? Zur Klärung einer komplexen kunstlerichen Praxis. En U. Mahlert (Ed.) Handbuch Üben. Grundlagen, Konzepte, Methoden. Wiesbaden: Breitkopf \& Härtel, 7-47.

Mantel, G. (1987). Cello üben: Eine Methodik des Übens für Streicher. Mainz: Schott.

Mantel, G. (2001). Einfach üben. 185 unübliche überezepte für Instrumentalisten. Mainz: Schott.

Mantel, G. (2006). Üben und Sprechen. En U. Mahlert (Ed.) Handbuch Üben. Grundlagen, Konzepte, Methoden. Wiesbaden: Breitkopf \& Härtel, 336-346.

Matthay, T. (1926). On memorizing and playing from memory and on the laws of practice generally. Oxford: Oxford University Press.

Meyer, L. (1973). Explaining Music: Essays and Explorations. Berkeley: University of California Press. 
Meyer, L. (1989). Style and Music: Theory, History and Ideology. Filadelfia: University of Pennsylvania Press.

Miller, G. A. (1956). The magic number seven, plus or minus two: some limits on our capacity for processing information. Psychological Review, 63, 81-97.

Mishra, J. (2002). A quantitative analysis of strategies employed in efficient and inefficient memorization. Bulletin of the Council for Research in Music Education, 152, 74-86.

Mishra, J. (2004). A Model of Musical Memory. En S.D. Lipscomb, R. Ashley, R. O. Gjerdingen, \& P. Webster (Eds.) Proceedings of the 8th Internacional Conference on Music Perception \& Cognition, Evanston, IL, 2004, Adelaide, Australia.

Mishra, J. (2005). A theoretical model of musical memorization. Psychomusicology, 19, 75-89.

Mishra, J. (2007). Correlating musical memorization styles and perceptual learning modalities. Visions of Research in Music Education, 9, 1-19.

Mishra, J. (2011). Influence of strategy on memorization efficiency. Music Performance Research. 4, 60-71. 
Mitchell, K. \& Johnson, M. (2000). Source Monitoring Attributing Mental Experiences. En E. Tulving \& F. Craik (Eds) The Oxford Handbook of Memory. Nueva York: Oxford University Press, 180197.

Narmour, E. (1988). On the relationship of analytical theory to performance and interpretation. En E. Narmour \& R. A. Solie (Eds.) Explorations in Music, the Arts, and Ideas. Stuyvesant: Pendragon, 317-340.

Neuhaus, H (1958/2004)) El arte del piano. Madrid: Real Musical 2004.

Nielsen, S. (1997). A case study of a church organ student preparing a musical work for performance. En H. Jorgensen \& A. Lehmann (Eds.) Does practice make perfect? Current theory and research on instrumental music practice. Oslo, Noruega: Norges Musikkoskole, 109-122.

Palmer, C. (2006). The Nature of Memory for Music Performance Skills. En E. Altenmüller, M. Wiesendanger \& J. Kesselring (Eds.) Music, Motor Control and the Brain. Nueva York: Oxford University Press, 39-53. 
Pohl, C. (2006). Mentales Üben. En U. Mahlert (Ed.) Handbuch Üben. Grundlagen, Konzepte, Methoden. Wiesbaden: Breitkopf \& Härtel, 287-311.

Reber, A. S. (1989). Implicit learning and tacit knowledge. Journal of Experimental Psychology: General, 118, 219-235.

Rink, J. (Ed.) (2002). Musical Performance. A Guide to Understanding. Cambridge University Press.

Röbke, P. (2006). Vom Umgang mit Fehern beim Üben. En U. Mahlert (Ed.) Handbuch Üben. Grundlagen, Konzepte, Methoden. Wiesbaden: Breitkopf \& Härtel, 370-382.

Roediger, H. \& Mcdermott, K. (2000). Distortions of Memory. En E. Tulving \& F. Craik (Eds) The Oxford Handbook of Memory Nueva York: Oxford University Press, 149-164.

Rossi, J. P. (2005). Psychologie de la mémoire. De la mémoire épisodique à la mémoire sémantique. Bruselas: Éditions de Boeck Université.

Rothstein, W. (1995), Analysis and the act of performance. En: John Rink (Ed.) The Practice of Performance. Cambridge: Cambridge University Press, 217-240. 
Schön, D. (1987). La formación de profesionales reflexivos. Hacia un nuevo diseño de la enseñanza y el aprendizaje de las profesiones (Traducción: Lourdes Montero y José Manuel Vez Jeremías). Madrid: Ediciones Paidós Ibérica.

Schmalfeldt, J. (1985). On the relation of analysis to performance: Beethoven's Bagatelles 2 and 5. Journal of Music Theory. 29/1, $1-31$.

Sloboda, J. (1985). The musical mind: The cognitive psychology of music. Oxford: Clarendon Press.

Sloboda, J.A. (1991) Music structure and emotional response: some empirical findings. Psychol. Music 19, 110-120.

Sloboda, J.; Davidson, J.; Howe, M. \& Moore, D. (1996). The role of practice in the development of performing musicians. British Journal of Psychology. (2), 87, 287-309.

Snyder, B. (2000). Music and memory: An introduction. Cambridge MA: MIT Press.

Süberkrüb, A. (2006), "Üben" in der musikalischen Lerntheorie von Edwin E. Gordon. En U. Mahlert (Ed.) Handbuch Üben. Grundlagen, Konzepte, Methoden. Wiesbaden: Breitkopf \& Härtel, 242-264. 
Temperley, D. (2001). The Cognition of Basic Musical Structures. Cambridge MA: MIT Press.

Thompson, S. \& Lehmann, A. (2004). Strategies for sight-reading and improvising music. En A. Williamon (Ed.) Musical Excellence. Strategies and Techniques to Enhance Performance. Nueva York: Oxford University Press, 143-159.

Tulving, E., \& Pearlstone, Z. (1966). Availability versus accessability of information in memory for words. Journal of Verbal Learning and Verbal Behavior, 5, 381-391.

Tulving, E., \& Thomson, D. (1973). Encoding specificity and retrieval processes in episodic memory. Psychological Review, 80, 352373.

Tureck, R. (1960). An Introduction to The Performance of Bach. Londres: Oxford University Press.

Varró, Margit (1929). Der lebendige Klavierunterricht. Seine Methodik und Psychologie. Hamburgo: Simrock Verlag.

Wessel, M. (2012). Üben. Proben. Karriere. 12 Interpreten im Gespräch. Kassel: Bärenreiter. 


\section{Referencias}

Williamon, A. (1999). The value of Performing from Memory. Psychology of Music, 27, 84-95.

Williamon, A. \& Valentine, E. (2002). The role of retrieval structures in memorizing music. Cognitive Psychology, 44, 1-32.

Wulf, G. \& Mornell, A. (2008). Insights about practice from the perspective of motor learning: a review. Music Performance Research. Vol. 2, 1-25.

Wulf, G., \& Shea, C.H. (2002). Principles derived from the study of simple motor skills do not generalize to complex skill learning. Psychonomic Bulletin and Review, 9, 185-211. 